\title{
The Effects of Sandstorms on the Climate of Northwestern China
}

\author{
Tiantian Hu, ${ }^{1}$ Di Wu, ${ }^{1}$ Yaohui Li, ${ }^{1,2}$ and Chenghai Wang' \\ ${ }^{1}$ Key Laboratory of Arid Climate Change and Disaster Reduction of Gansu Province, \\ College of Atmosphere Science, Lanzhou University, Lanzhou 730000, China \\ ${ }^{2}$ Institute of Arid Meteorology, China Meteorological Administration, Lanzhou, China \\ Correspondence should be addressed to Chenghai Wang; wch@lzu.edu.cn
}

Received 3 September 2016; Revised 27 February 2017; Accepted 12 March 2017; Published 28 March 2017

Academic Editor: Panuganti C. S. Devara

Copyright (C) 2017 Tiantian Hu et al. This is an open access article distributed under the Creative Commons Attribution License, which permits unrestricted use, distribution, and reproduction in any medium, provided the original work is properly cited.

\begin{abstract}
In this paper, we investigate the observational direct radiation characteristics of several sandstorm events in Northwestern China (NWC). A simulating sensitivity experiment was designed to reduce the downward radiation in RegCM4 to investigate the climatic impacts and persistence of the direct radiation effect (DRE) from dust aerosols in sandstorms. The results show that dust aerosols in sandstorms can change the radiation heating rate of the atmosphere, heating the air in the middle and low troposphere and cooling Earth's surface. The climate effects of continuous and intense sandstorms in April in NWC can reach downstream areas such as Southeast and Northeast China and can persist for months. The dust aerosols in sandstorms can enhance diabatic heating and moisture loss. Therefore, dust storms lead to the environment in NWC becoming warmer and dryer. Through analysis of the dust tracer total burden, we identified that the enhancement of the dust total burden in the arid region illustrated that the DRE of dust aerosol in sandstorm process can react with the dust emission, thus forming a self-feedback loop. The DRE can persist three months.
\end{abstract}

\section{Introduction}

With the expansion of desertification, sandstorm activities occur more frequently [1]. Mineral dust is the most important component of natural aerosols, with $1000-4000 \mathrm{Tg}$ of dust emitted every year [2]. Research has suggested that dust aerosol has strong impacts on regional climate through changing the radiative forcing [3]. The positive anomalies of dust are associated with a considerable reduction in surface shortwave radiation $[4,5]$, the surface is cooled, and the atmosphere is heated by the backscatter of dust aerosols [6].

In general, the climate effects of dust aerosols can be divided into 3 categories: the direct radiation effect (DRE) occurs through scattering and absorbing solar direct radiation; the indirect effect of climate is where the aerosols act as cloud condensation nuclei or ice nuclei, thus changing the microphysics and optical properties as well as the precipitation efficiency of cloud (cloud reflection and ice nucleation effects); and the semidirect effect occurs when the strong absorption of radiation of aerosols (such as soot) releases thermal radiation following the prior absorption of solar radiation energy, thus heating the air mass and increasing the static stability relative to the surface. This can also lead to cloud droplet evaporation and cause a decrease in cloud cover and cloud albedo, thus affecting the climate [7]. Kaspari et al. (2009) used ice cores to analyze the sources and variations in atmospheric dust from 1650 to 2002 and suggested that the chemical composition of dust varies seasonally, and peak dust concentration occurs during the winter and spring months [8].

Seinfeld et al. (2004) examined ACE-Asia in situ measurements and found that the single-scatter albedo of pure dust's diameter at $500 \mathrm{~nm}$ is 0.98 [9]. This suggests the dust changes the shortwave radiation, mainly though scatter. Northwest China (NWC) has areas covered by the Gobi Desert and loess regions, which are major source regions of Asian dust. Zhao et al. (2015) used an aerosol-climate coupled system to investigate the direct climatic effects of dust aerosol on global arid and semiarid regions and concluded that the cooling effects of dust aerosols can lead to anomalies in evaporation, circulation, and global precipitation [10]. During sandstorm events, the temperature and relative humidity in the atmosphere are changed, which affects atmospheric stratification features and precipitation. 
TABLE 1: The radiation force of aerosols in sandstorms cases.

\begin{tabular}{|c|c|c|c|}
\hline Time & Location & Radiation & Reference \\
\hline $\begin{array}{l}\text { From April to September, } \\
2001\end{array}$ & $\begin{array}{c}\text { Tengger Desert; } \\
\left(37^{\circ} 27^{\prime} 535^{\prime \prime} \mathrm{N}, 105^{\circ} 00^{\prime} 643^{\prime \prime} \mathrm{E},\right. \\
\text { altitude } 1339 \mathrm{~m})\end{array}$ & $\begin{array}{c}\text { The global radiation reduced } 10-90 \% \text { in } \\
\text { sand and dust weather; average } \\
\text { attenuation is about } 38 \% \text {. }\end{array}$ & Xin et al. (2003) [16] \\
\hline April 10, 2006 & $\begin{array}{c}\text { Taklimakan Desert; } \\
\left(83^{\circ} 40^{\prime} \mathrm{E}, 39^{\circ} \mathrm{N} \text {, altitude } 1099.3 \mathrm{~m}\right)\end{array}$ & The global radiation reduced $94.5 \%$. & Li et al. (2011) [17] \\
\hline April 22, 2007 & $\begin{array}{c}\text { Taklimakan Desert hinterland } \\
\left(83^{\circ} 39^{\prime} \mathrm{E}, 38^{\circ} 58^{\prime} \mathrm{N} \text {, altitude }\right. \\
1099.3 \mathrm{~m})\end{array}$ & $\begin{array}{l}\text { Global radiation reduced by } 59 \% \text {; the } \\
\text { average dust radiation force in } \\
\text { Taklimakan Desert is about } 50 \% \text { during } \\
\text { the observation. }\end{array}$ & Kong et al. (2008) [18] \\
\hline April 23, 1991 & $\begin{array}{l}\text { Desert station near Zhangye; } \\
\left(39^{\circ} 26^{\prime} \mathrm{N}, 100^{\circ} 12^{\prime} \mathrm{E}\right)\end{array}$ & $\begin{array}{l}\text { The surface global radiation reduced } \\
\qquad 83.1 \mathrm{~W} \mathrm{~m}^{-2}\end{array}$ & Shen and Wei (2000) [19] \\
\hline April 23, 1991 & $\begin{array}{l}\text { Zhangye Station; } \\
\left(38^{\circ} 50^{\prime} \mathrm{N}, 100^{\circ} 23^{\prime} \mathrm{E}\right)\end{array}$ & $\begin{array}{l}\text { The surface global radiation reduced } \\
60.0 \mathrm{~W} \mathrm{~m}^{-2}\end{array}$ & Shen and Wei (2000) [19] \\
\hline March 27, 2004 & Beijing & $\begin{array}{c}\text { The global radiation reduced } 37.8 \% \\
\text { during the sandstorm. }\end{array}$ & Hu et al. (2005) [20] \\
\hline
\end{tabular}

Wang et al. (2013) used the Weather Research and Forecasting (WRF) model to simulate the occurrence of a dust storm in Northern China during April 22-25, 2009, and suggested that the diabatic heating effect plays an important role in the sandstorm development and maintenance [11]. The simulation with RegCM4 shows that dust aerosols might increase the wet season precipitation in the Arabian Peninsula; the dust plumes exert a negative (positive) radiative forcing at the surface (top of the atmosphere) by reducing incoming solar radiation, reaching the ground and locally heating up the atmospheric column [12]. Using coupled and uncoupled dust experiment with RegCM4, Sun et al. (2012) analyzed the spatiotemporal distribution of dust aerosols and their climatic impact though direct radiation forcing over East Asia and found that dust aerosol-induced cooling leads to the formation of a cyclonic circulation in the middle and lower troposphere in NWC that further excites downstream an anticyclonic circulation (the Yellow River Loop) and a cyclonic circulation (East China Sea, ECS) [13].

Most of the studies investigated the climate effects of the dust aerosols by considering radiation. The radiative forcing caused by dust aerosols in sandstorms can cause local surface temperature decreases and form a regional cold source. Usually, there are 3-5 sandstorms in NWC in spring every year and each sandstorm lasts for 3-5 days. It remains uncertain what the major changes are in the atmospheric stratification during a sandstorm process, what climatic effects are associated with continuous heavy sandstorms process in a month, how long such climate effects persist, which climatic changes may be caused in downstream areas, and what their extent may be. Furthermore, the potential subsequent effect on future dust emissions is also uncertain. Answering these questions will improve our understanding of the impacts and mechanisms behind dust storms. This paper will investigate the impacts of the DRE of dust aerosols in sandstorms on the environment in NWC. In Section 2, the observed global and DRE characteristics during sandstorms are presented. The data and model descriptions and experimental design in this study are provided in Section 3. The DRE of dust aerosols in sandstorms in NWC are illustrated in Section 4. Section 5 provides a summary and conclusion.

\section{The Observational Characteristics of Radiation Changes during Sandstorms}

Sandstorms cause entrainment of sand mass into the air, leading to the sharp decrease of radiation flux in the atmosphere near the surface and reducing the local temperature; such persistent cooling will cause the region to become a cold source [14]. The soil dust aerosols redistribute heating from the surface to within the dust layer [15]. Table 1 shows the radiation changes observed in sandstorm events that have occurred in NWC. On the desert sunny days, because the cloud cover is low and the air is clean, dust aerosols only marginally influence solar radiation reduction in the air and a large amount of global radiation can reach the surface. However, during sandstorm weather, the abundant dust source and dry surface in the desert provide optimum conditions for dust emission and the high dust concentration in the air rapidly reduces direct radiation. For example, at the Tengger Desert experimental station $\left(37^{\circ} 28^{\prime} \mathrm{N}, 105^{\circ} 01^{\prime} \mathrm{E}\right)$, during April to September in 2001, it was observed that the solar radiation reduction during dust weather reached about $10-90 \%$ and the average attenuation was about 38\% [16]. During 2 sandstorms that occurred in the Taklimakan Desert hinterland $\left(38^{\circ} 58^{\prime} \mathrm{N}, 83^{\circ} 39^{\prime} \mathrm{E}\right)$ on April 10, 2006, [17] and April 22, 2007 [18], the global radiation reduced about $94.5 \%$ and 59\%, respectively. Kong et al. (2008) summarized that the observed net radiation during sandstorms in the Taklimakan Desert reduced about $50 \%$ on average [18].

However, in the NWC semiarid region, because of the different geological structure, the vegetation cover on the underlying surface, and the influence of the surrounding terrain, the intensity of wind is weaker and the burden of sand is low compared with the desert; therefore, a reduction of radiation by dust aerosols is also different compared with the desert area [19]. The Hexi Corridor in NWC is a high 
TABLE 2: The frequency of sandstorm at the five provincial capital cities in NWC from 2004 to 2012 (day $\mathrm{a}^{-1}$ ).

\begin{tabular}{lccccc}
\hline City & Total days & Days in March & Days in April & Days in May & Days in June \\
\hline Xian & 6.0 & 0.7 & 0.7 & 0.5 & 1.4 \\
Lanzhou & 7.6 & 2.8 & 2.7 & 0.0 & 0.2 \\
Xining & 1.5 & 0.3 & 1.0 & 3.0 & 0.0 \\
Yinchuan & 21.9 & 3.3 & 0.8 & 0.2 & 0.2 \\
Urumchi & 1.4 & 0.0 & & 0.0 \\
\hline
\end{tabular}

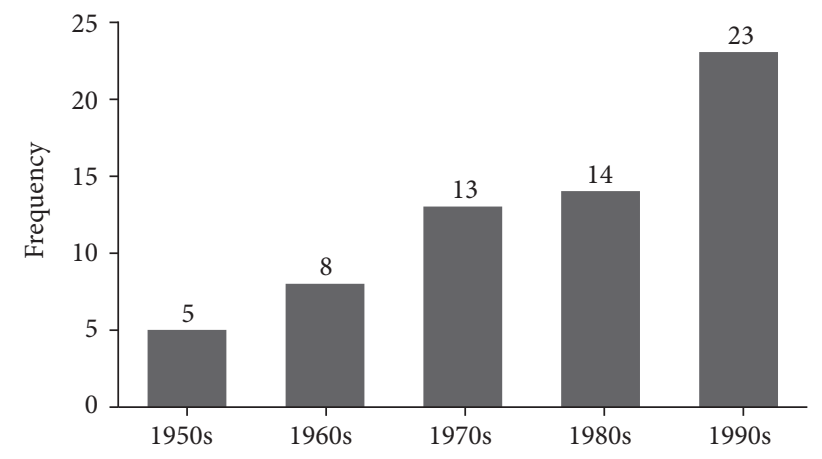

FIGURE 1: Inter-decadal change in sandstorm frequency in NWC between 1950 and 2000 .

incidence area of sandstorms, blowing sand, and floating dust. For example, from the last ten days of February to the first ten-day period of May 1991, there were 11 observed sandstorms in Zhangye Station $\left(38^{\circ} 50^{\prime} \mathrm{N}, 100^{\circ} 23^{\prime} \mathrm{E}\right)$ and the adjacent desert station $\left(39^{\circ} 26^{\prime} \mathrm{N}, 100^{\circ} 12^{\prime} \mathrm{E}\right)$ and the air was continually muddy during that period. On April 23 (a muddy day), the 2 stations measured higher planetary albedo, compared with clear days and, on muddy days, the observed surface global radiation reduced $60.0 \mathrm{~W} \mathrm{~m}^{-2}$ and $83.1 \mathrm{~W} \mathrm{~m}^{-2}$ at the Zhangye and desert stations, respectively [19]. Similar cooling effects occurred in East China; even though this region is far away from the sand source, it is also subject to frequent sandstorm activity. During a sandstorm observed in Beijing on March 27, 2004, the global radiation reduced 37.8\% of a clear day [20].

Studies have suggested that the frequency of sandstorms is increasing in Northwest China (NWC) in recent years $[21,22]$. Figure 1 shows the inter-decadal change in sandstorm frequency in NWC from 1950 to 2000; the sandstorm occurrence frequency was 5 times per year during 1950-1960 and then increased sharply every 10 years, reaching 23 times per year during 1990-2010. It is worth noting that Figure 1 only shows the sandstorm frequency in NWC during 1950-2000; however, some researches suggested that sandstorm occurrence days show a decreasing trend from 1950 to 2000 in the whole China and East Asia, as well as several stations in NWC [23-25]. It is not conflicting because of the difference of statistical method. According to the sandstorm occurrence frequency statistics in spring during 2004 to 2012 at 5 provincial capital cities in NWC (Table 2), sandstorms occurred every spring, especially in March and April from 2004 to 2012 (the position of the 5 provincial capital cities is shown in Figure 2). Otherwise, sandstorms

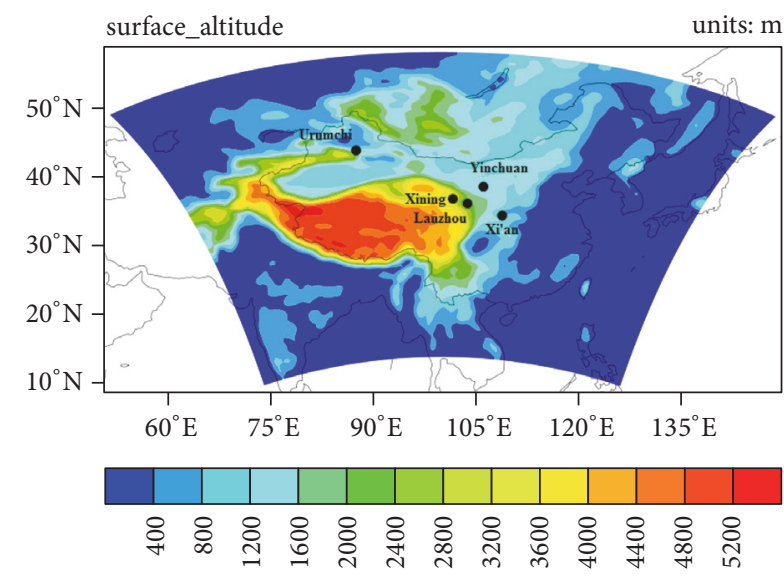

FIGURE 2: The five stations in provincial capital cities, as presented in Table 2 (black points), and the domain of the RegCM4 simulation. Shading denotes surface model elevation (m).

occurred in Urumchi almost half of the years between 2004 and 2012. The number of sandstorm days at Urumchi is 1.4 days per year during the 9 years (2004-2012). The maximum number of sandstorm days occurs in Yinchuan, at 21.9 dust storm days per year on average in the 9 years. In Lanzhou, dust storms occurred 7.6 days per year on average; otherwise, Yinchuan and Lanzhou are located downstream of the main dust source.

Table 3 shows the radiation flux changes in 5 sandstorm processes during 2009 to 2011 from observed data at Lanzhou Station $\left(36^{\circ} 03^{\prime} \mathrm{N}, 103^{\circ} 53^{\prime} \mathrm{E}\right)$. The observed data is $12 \mathrm{~h}$ of radiation exposure. The reduction of the global radiation during the sandstorm process is substantial due to the sandstorm strength. In 5 sandstorm processes, the global radiation decreasing rate ranges from $4 \%$ to $36 \%$; on average, the decrease is $21 \%$.

Figure 3 shows the change in the ground meteorological elements and radiation during a dust weather process in Lanzhou from April 23 to 24, 2009, using the observed data at Lanzhou Station $\left(36^{\circ} 03^{\prime} \mathrm{N}, 103^{\circ} 53^{\prime} \mathrm{E}\right)$. The 6-hour visibility sharply decreased at 14:00 (LZT) April 23, which indicates the strongest level of dust concentration (Figure 3(a)). The visibility was only $200 \mathrm{~m}$ at this time and it remained lower than $500 \mathrm{~m}$ from 20:00 (LZT) April 23 to 2:00 (LZT) April 24 , which indicates that the polluted air persisted for at least 12 hours. The global radiation reached a minimum value at 12:00 (LZT) April 23 and the irradiance was only $113.9 \mathrm{~W} \mathrm{~m}^{-2}$. In contrast, at the same time on April 24, 
TABLE 3: Radiation flux changes in five sandstorm processes in Lanzhou during 2009 to 2011.

\begin{tabular}{lcccc}
\hline Sandstorm date & Global radiation $\left(\mathrm{MJ} \mathrm{m}^{-2}\right)$ & Clear sky date & Global radiation $\left(\mathrm{MJ} \mathrm{m} \mathrm{m}^{-2}\right)$ & Decrease rate \\
\hline $09 / 04 / 2009$ & 235 & $05 / 04 / 2009$ & 322 & 0.27 \\
$24 / 04 / 2009$ & 236 & $20 / 04 / 2009$ & 277 & 0.26 \\
$19 / 03 / 2009$ & 266 & $16 / 03 / 2009$ & 299 & 0.04 \\
$09 / 04 / 2010$ & 275 & $30 / 04 / 2010$ & 318 & 0.08 \\
$29 / 04 / 2011$ & 202 & $05 / 05 / 2011$ & 307.2 & 0.36 \\
\hline Average & 242.8 & & & 0.21 \\
\hline
\end{tabular}

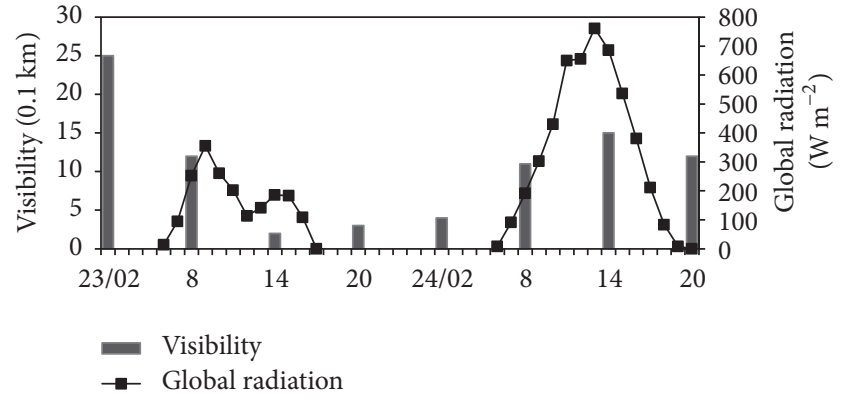

(a)

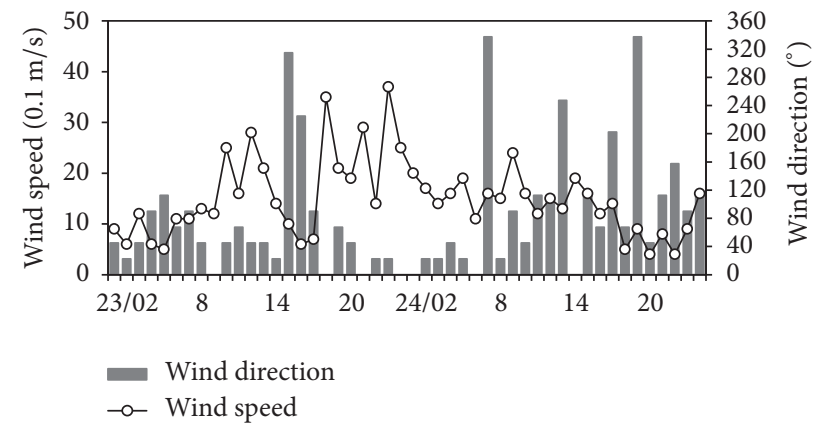

(b)

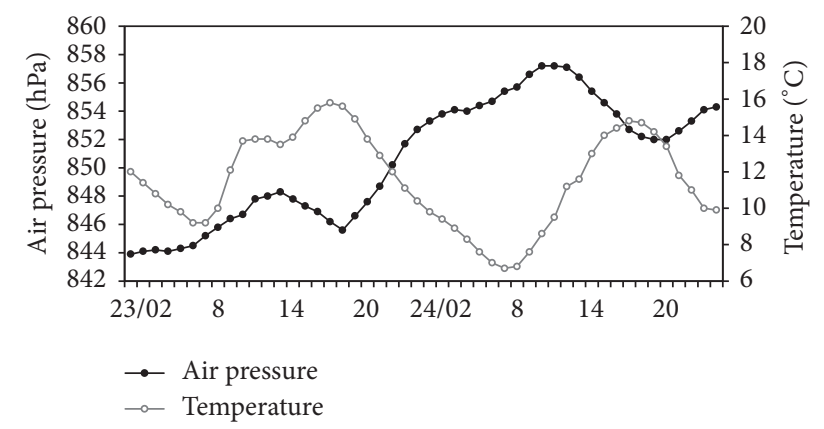

(c)

FIGURE 3: Evolution of the observational elements from April 23 to 24, 2009 (BJT). (a) 6-hour visibility and irradiance; (b) hourly wind speed and wind direction; (c) air pressure and temperature.

the irradiance was $655.6 \mathrm{~W} \mathrm{~m}^{-2}$, indicating that the global radiation reduces $82 \%$ during the sand process. The wind speed sharply decreased near 14:00 (LZT) on April 23 and the wind direction turned from the northeast to the southeast (Figure 3(b)). After 17:00 (LZT) on April 23, the wind speed increased considerably. The pressure decreased at around
TABle 4: Details of the regional climate model version 4.4 (RegCM4.4) scheme.

\begin{tabular}{lc}
\hline Term & Scheme \\
\hline Center of lattice & $35^{\circ} \mathrm{N}, 100^{\circ} \mathrm{E}$ \\
Horizontal resolution & $50 \mathrm{~km}$ \\
Time steps & $100 \mathrm{~s}$ \\
Lateral boundary condition & Relaxation, exponential \\
scheme & technique \\
Boundary layer scheme & Holtslag [26] \\
Cumulus convection scheme & Emanuel [27] \\
Ocean flux scheme & Zeng \\
Land surface model & Biosphere-Atmosphere Transfer \\
Chemistry scheme & Scheme (BATS) \\
\hline
\end{tabular}

14:00 (LZT) on April 23, while the temperature increased during that period (Figure 3(c)). The air pressure increased and the temperature decreased at 18:00 (LZT) at sunset on April 23.

Above observations show that, on average, the amount of global radiation arriving at Earth's surface will reduce during sandstorm events with an average reduction of about $20-60 \%$. The month with the highest frequency of sandstorms is usually April in NWC.

\section{Model Description and Experiment Design}

This work employs the regional climate model version 4.4 (RegCM4.4), with the chemical module working, which was developed by the Abdus Salam International Centre for Theoretical Physics (ICTP). The model is fully described in a special issue of Climate Review [28]. The model has $\sigma$ vertical coordinates and the whole atmosphere is divided into 18 layers. The domain of simulation is given in Figure 2. The center of the lattice is $35^{\circ} \mathrm{N}, 100^{\circ} \mathrm{E}$ and the horizontal resolution is $50 \mathrm{~km}$ (Table 4). We use the European Centre for Medium-Range Weather Forecasts Interim (ERA-Interim) dataset to drive RegCM4 [29]. The radiation scheme in the model is from National Center for Atmospheric Research (NCAR) Community Climate Model version 3 (CCM3), which is described in Kiehl et al. (1996) [30]. For this simulation, we selected the Biosphere-Atmosphere Transfer 
Scheme (BATS) [31] for surface process representation, the Emanuel (1991) scheme [27] as the cumulus convection parameterization scheme, and the Holtslag (1990) scheme [26] as the planetary boundary layer scheme and used the relaxation, exponential technique for the lateral boundary conditions scheme. The dust chemical tracers were activated in the model using four kinds of dust bins scheme. The mineral dust simulation of RegCM4.4 is described by Laurent et al. (2008) [32] and Alfaro and Gomes (2001) [33]. The 4 bins calculate the emission and tracer of dust aerosols at $0.01,1.00$, 2.50 , and 5.00 micrometers particle diameter.

3.1. Radiation Parameterization Schemes. The RegCM4 model uses the radiation scheme of NCAR CCM3, which uses the $\delta$-Eddington approximation when calculating the solar radiation. A similar derivation of the downward flux is straightforward. The resulting expressions for the upward and downward flux are as follows:

$$
\begin{aligned}
F_{\text {up }}= & \frac{e^{-\tau^{*} / \mu_{0}} R_{\text {up }}\left(\mu_{0}\right)+\left(T_{\mathrm{dn}}\left(\mu_{0}\right)-e^{-\tau^{*} / \mu_{0}}\right) \bar{R}_{\mathrm{up}}}{1-\bar{R}_{\mathrm{dn}} \bar{R}_{\text {up }}}, \\
F_{\mathrm{dn}=} & e^{-\tau^{*} / \mu_{0}} \\
& +\frac{\left(T_{\mathrm{dn}}\left(\mu_{0}\right)-e^{-\tau^{*} / \mu_{0}}\right)+e^{-\tau^{*} / \mu_{0}} R_{\text {up }}\left(\mu_{0}\right) \bar{R}_{\mathrm{dn}}}{1-\bar{R}_{\mathrm{dn}} \bar{R}_{\text {up }}},
\end{aligned}
$$

where $e^{-\tau^{*} / \mu_{0}}$ is the direct beam transmission from top of atmosphere to the interface $\left(\tau^{*}\right.$ is the scaled optical depth from top of atmosphere to the interface), $R_{\text {up }}\left(\mu_{0}\right)$ is the reflectivity of atmosphere to the interface, $T_{\mathrm{dn}}\left(\mu_{0}\right)$ is the total transmission to direct solar radiation incident from above to the entire atmosphere above the interface, $\bar{R}_{\text {up }}$ is the reflectivity of atmosphere below the interface to diffuse radiation from above, and $\bar{R}_{\mathrm{dn}}$ is the reflectivity of atmosphere above the interface to diffuse radiation from below.

The upward and downward spectral fluxes at each interface are summed to evaluate the spectrally integrated fluxes and then differenced to produce the solar heating rate:

$$
\begin{aligned}
& Q_{\text {sol }} \\
& \qquad=\frac{g}{c_{p}} \frac{F_{\mathrm{dn}}\left(p_{k+1}\right)-F_{\mathrm{up}}\left(p_{k+1}\right)-F_{\mathrm{dn}}\left(p_{k}\right)+F_{\mathrm{up}}\left(p_{k}\right)}{p_{k+1}-p_{k}} .
\end{aligned}
$$

This is added to the nonlinear term $(Q)$ in the thermodynamic equation.

Vertical distribution of aerosols has a great impact on the heating rate profile, which provides more details about dust aerosol DRE on different atmospheric levels than radiation force. Over the Taklimakan Desert, dust aerosols can heat the atmosphere by up to 1,2 , and $3 \mathrm{Kd}^{-1}$ (daily mean values) under light, moderate, and heavy dust conditions, respectively; the maximum daily mean of radiative heating rate can reach $5.5 \mathrm{~K} \mathrm{~d}^{-1}$ at $5 \mathrm{~km}$, at the location of the dust layer [34].

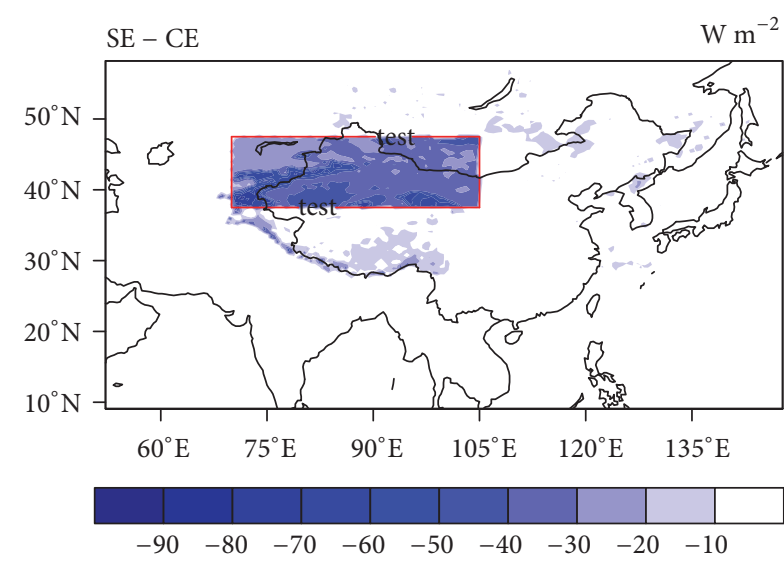

FIGURE 4: Difference of surface net downward shortwave radiation flux $\left(\mathrm{W} \mathrm{m}^{-2}\right)$ between sensitivity experiment (SE) and control experiment (CE) in April averaged from 2001 to 2010.

3.2. Sensitivity Experiment Design. In order to investigate the climate effects of dust aerosols in arid regions, a control experiment (CE) was established in which there were no changes during the whole integration. A sensitivity experiment (SE) was designed as follows: as mentioned in Section 2, the amount of global radiation arriving at Earth's surface will reduce during sandstorm events with an average reduction of about $20-60 \%$; the SE adopted the middle value of $40 \%$ to reduce downward radiation flux every April from 2001 to 2010 in the region of $37.5^{\circ}-47.5^{\circ} \mathrm{N}, 70^{\circ}-105^{\circ} \mathrm{E}$, where the sandstorm is frequent (Figure 4). The downward radiation flux is reduced $5 \%$ per layer in the 8 boot layers of the $\sigma$ vertical coordinate, which corresponds with around $700 \mathrm{hPa}$. The altitude of the eighth layer is about $2 \mathrm{~km}$; therefore, the downward radiation reaching the surface is only around $60 \%$. Because of the changing downward shortwave radiation fluxes, $Q_{\text {sol }}$ enhanced subsequently in response to the effects of scattered radiation, thus heating the air.

The simulation time was from 01 January 2001 to 01 March 2011. In particular, the first 2 months were regarded as the spin-up period, and the results from 01 March 2001 to 01 March 2011 were used for analysis.

To validate the performance of the RegCM4.4 model for the simulation in China, Figure 5 shows the comparison of the precipitation and temperature between simulated results in CE and observed data from 668 weather stations in China. Compared to Figures 5(a) and 5(c), Figures 5(b) and 5(d) indicate that the model can reproduce the basic distribution characteristics of $2 \mathrm{~m}$ temperature and precipitation in China. The $2 \mathrm{~m}$ temperature in simulation in most of the regions in China is about $1-2^{\circ} \mathrm{C}$ lower than observational data except in high and complex terrain. The simulation reproduces the precipitation distribution in China (Figure 5(d)), except in southwest China. The number of observational stations is relatively sparse in Tibetan Plateau which may cause the observed biases. Therefore, the model used in this study has a good performance and can be used for the SE. 


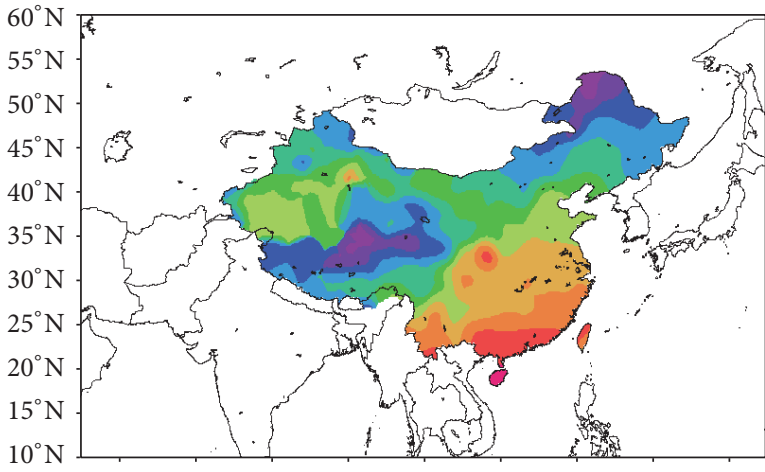

$60^{\circ} \mathrm{E} \quad 70^{\circ} \mathrm{E} \quad 80^{\circ} \mathrm{E} \quad 90^{\circ} \mathrm{E} \quad 100^{\circ} \mathrm{E} 110^{\circ} \mathrm{E} 120^{\circ} \mathrm{E} 130^{\circ} \mathrm{E} 140^{\circ} \mathrm{E}$

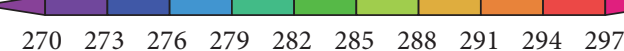

(a) Obs: $2 \mathrm{~m}$ temperature $(\mathrm{K})$

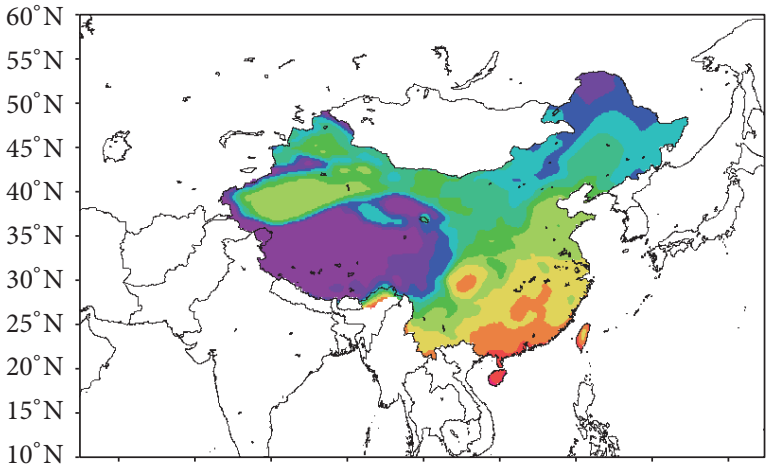

$60^{\circ} \mathrm{E} \quad 70^{\circ} \mathrm{E} \quad 80^{\circ} \mathrm{E} \quad 90^{\circ} \mathrm{E} \quad 100^{\circ} \mathrm{E} \quad 110^{\circ} \mathrm{E} \quad 120^{\circ} \mathrm{E} \quad 130^{\circ} \mathrm{E} \quad 140^{\circ} \mathrm{E}$

$\begin{array}{llllllllll}270 & 273 & 276 & 279 & 282 & 285 & 288 & 291 & 294 & 297\end{array}$

(c) CE: $2 \mathrm{~m}$ temperature $(\mathrm{K})$

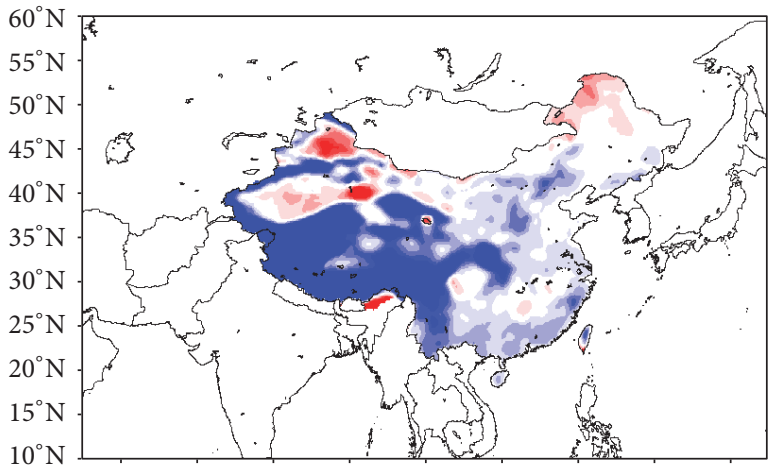

$60^{\circ} \mathrm{E} \quad 70^{\circ} \mathrm{E} \quad 80^{\circ} \mathrm{E} \quad 90^{\circ} \mathrm{E} \quad 100^{\circ} \mathrm{E} 110^{\circ} \mathrm{E} 120^{\circ} \mathrm{E} 130^{\circ} \mathrm{E} 140^{\circ} \mathrm{E}$

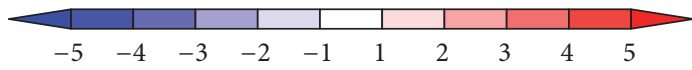

(e) CE - Obs: $2 \mathrm{~m}$ temperature (K)

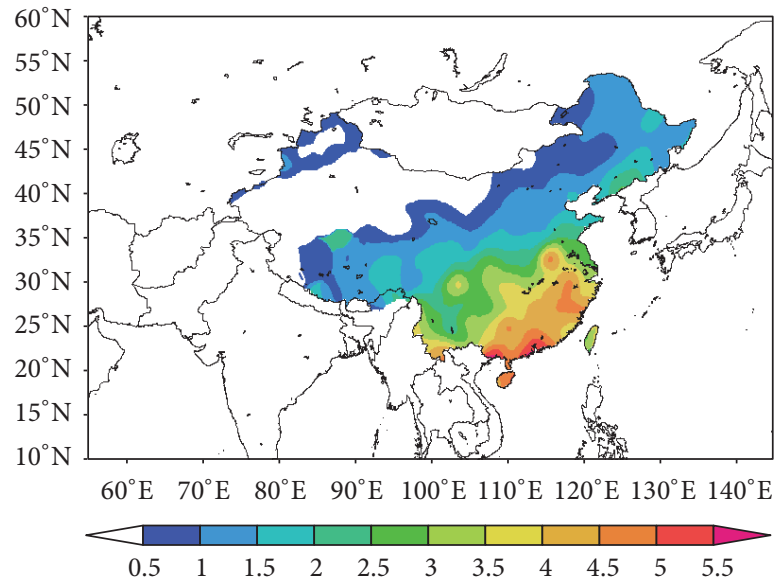

(b) Obs: precipitation $(\mathrm{mm} / \mathrm{d})$

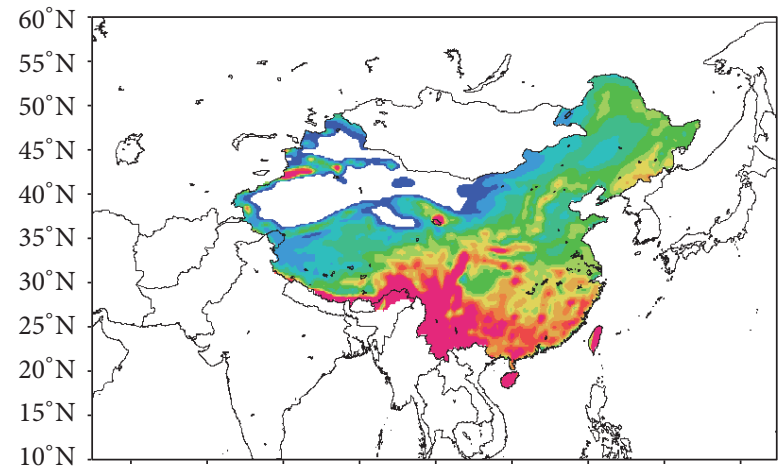

$60^{\circ} \mathrm{E} \quad 70^{\circ} \mathrm{E} \quad 80^{\circ} \mathrm{E} \quad 90^{\circ} \mathrm{E} \quad 100^{\circ} \mathrm{E} 110^{\circ} \mathrm{E} 120^{\circ} \mathrm{E} 130^{\circ} \mathrm{E} 140^{\circ} \mathrm{E}$

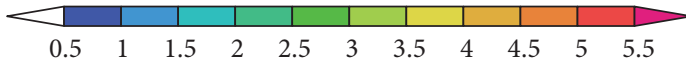

(d) CE: precipitation $(\mathrm{mm} / \mathrm{d})$

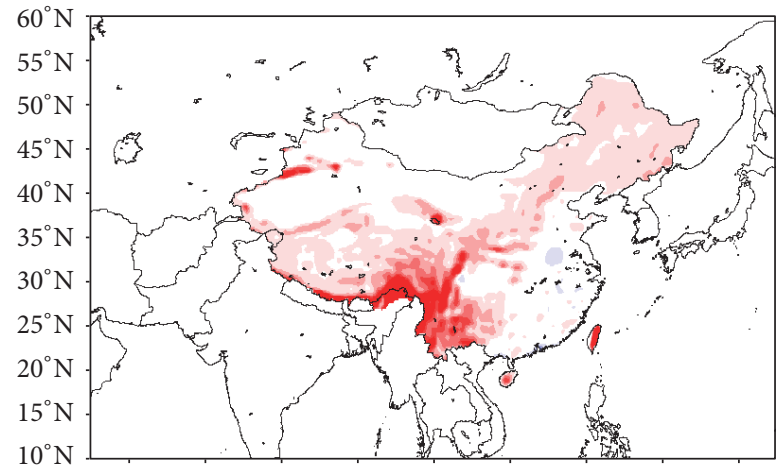

$60^{\circ} \mathrm{E} \quad 70^{\circ} \mathrm{E} \quad 80^{\circ} \mathrm{E} \quad 90^{\circ} \mathrm{E} \quad 100^{\circ} \mathrm{E} 110^{\circ} \mathrm{E} 120^{\circ} \mathrm{E} 130^{\circ} \mathrm{E} 140^{\circ} \mathrm{E}$

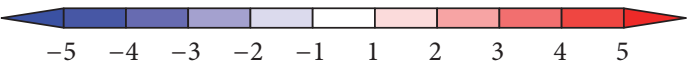

(f) $\mathrm{CE}-$ Obs: precipitation $(\mathrm{mm} / \mathrm{d})$

FIGURE 5: Comparison of mean temperature and precipitation averaged from 1 March 2001 to 1 March 2011 between observation and simulation. (a) Observed $2 \mathrm{~m}$ temperature (K) from 668 stations; (b) observed precipitation (mm/d) from 668 stations; (c) simulated $2 \mathrm{~m}$ temperature $(\mathrm{K})$; (d) simulated precipitation $(\mathrm{mm} / \mathrm{d})$; (e) differences of $2 \mathrm{~m}$ temperature $(\mathrm{K})$; and (f) differences of precipitation $(\mathrm{mm} / \mathrm{d})$ between simulation and observation (simulation - observation). 


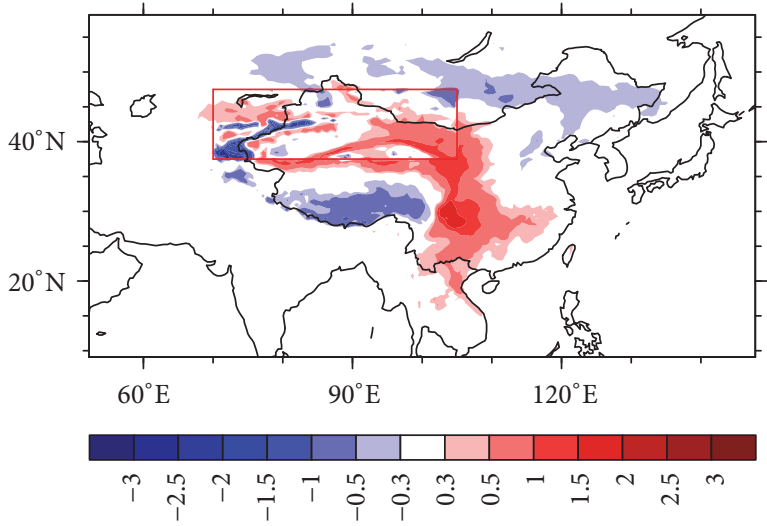

(a)

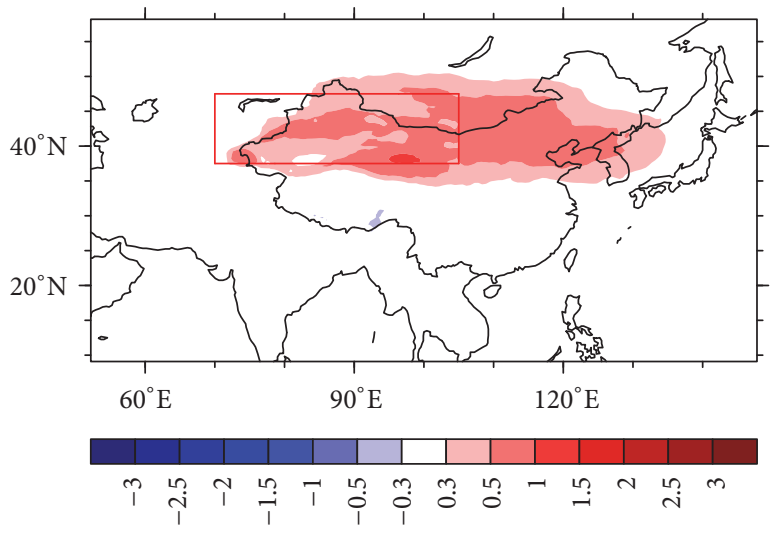

(c)

Figure 6: The temperature DIF (SE - CE; K) at the height of (a) $2 \mathrm{~m}$, (b) $700 \mathrm{hPa}$, (c) $500 \mathrm{hPa}$, and (d) $200 \mathrm{hPa}$ in April averaged from 2001 to 2010 .

\section{The Climate Effects of Sandstorms}

4.1. Temperature. Because of the reduction of downward radiation in SE, that is, during sandstorm processes, the reduced radiant energy transforms into thermal energy and stays in the atmosphere. This changes the heating rate of the atmospheric stratification, causing the air temperature in experiment region to increase at this time. The difference (DIF) of air temperature (SE - CE) in April NWC at $700 \mathrm{hPa}$ (Figure 6(b)) is the largest, compared with $2 \mathrm{~m}$ height (Figure 6(a)) and at $500 \mathrm{hPa}$ (Figure 6(c)). This is because the height of $700 \mathrm{hPa}$ is near the eighth layer of the $\sigma$ coordinate, where heat accumulates. Because less downward radiation reaches Earth's surface, the surface becomes a cold source in sandstorms and emits less longwave radiation to heat the tropopause. The temperature DIF (SE - CE) in April NWC becomes negative at $200 \mathrm{hPa}$ (Figure 6(d)). At the heights of $2 \mathrm{~m}$ and $700 \mathrm{hPa}$ in April, the area of temperature increase extends from NWC to Northeast and Southwest China, because of the transport of warm air by the wind from the north and west.

4.2. Atmospheric Stratification. Figure 7 shows the skew-T stratification curve during an observed sandstorm process

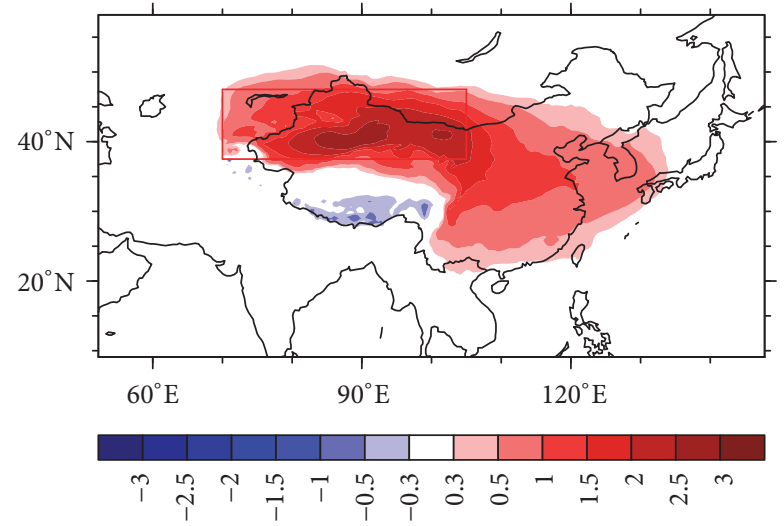

(b)

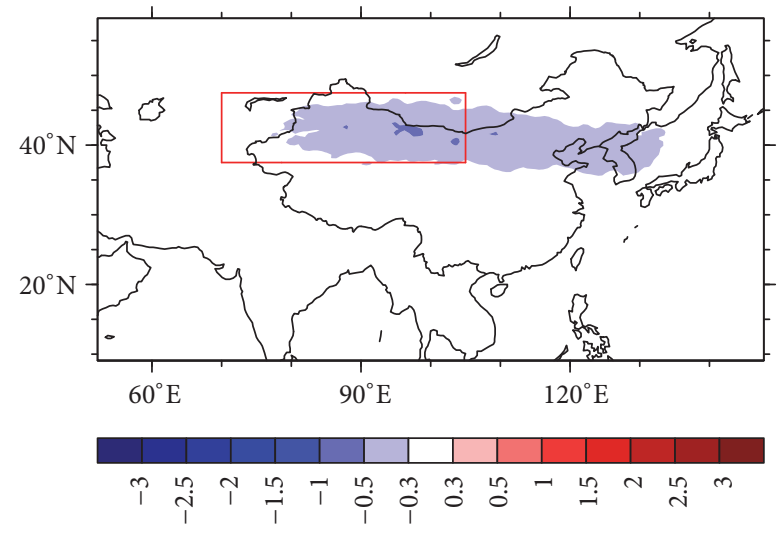

(d) at Minqing station $\left(38^{\circ} 38^{\prime} \mathrm{N}, 103^{\circ} 05^{\prime} \mathrm{E}\right)$ which is included in NWC $\left(37.5^{\circ} \mathrm{N}-47.5^{\circ} \mathrm{N}, 70^{\circ} \mathrm{E}-105^{\circ} \mathrm{E}\right)$, on April 24, 2010. The observed dust storm occurred at 12:00 UTC (20:00 LZT) at that station (Shen et al. 2014). At 00:00 UTC (8:00 LZT) (Figure $7(\mathrm{a})$ ), the dew point temperature is higher below $400 \mathrm{hPa}$, indicating that the moisture is greater in SE than in $\mathrm{CE}$ in the morning, but the air temperature is lower in SE below $700 \mathrm{hPa}$ near the surface at morning. This is because the cold effects from the surface dominate the lower atmosphere before sunrise. There was a substantial difference in air temperature in SE from $700 \mathrm{hPa}$ to $400 \mathrm{hPa}$, relative to $\mathrm{CE}$ at the same heights, because of the heating effects of the dust aerosols. At 06:00 UTC (14:00 LZT) (Figure 7(b)), the temperature is higher in SE than in CE from the surface to around $700 \mathrm{hPa}$, and the moisture presents lower in SE between $700 \mathrm{hPa}$ and $250 \mathrm{hPa}$ than CE, which reverses above $250 \mathrm{hPa}$ in the afternoon. At 12:00 UTC (20:00 LZT) (Figure 7(c)), when the observed sandstorm occurred, the temperature is higher in SE than in $\mathrm{CE}$ while the moisture is lower in SE than in CE, especially below $400 \mathrm{hPa}$ in the evening. At 18:00 UTC (2:00 LZT) (Figure $7(\mathrm{~d}))$, the moisture is still lower and the temperature is higher in the SE than in CE, but the DIF of temperature seems smaller at night compared with the evening. During the observed 


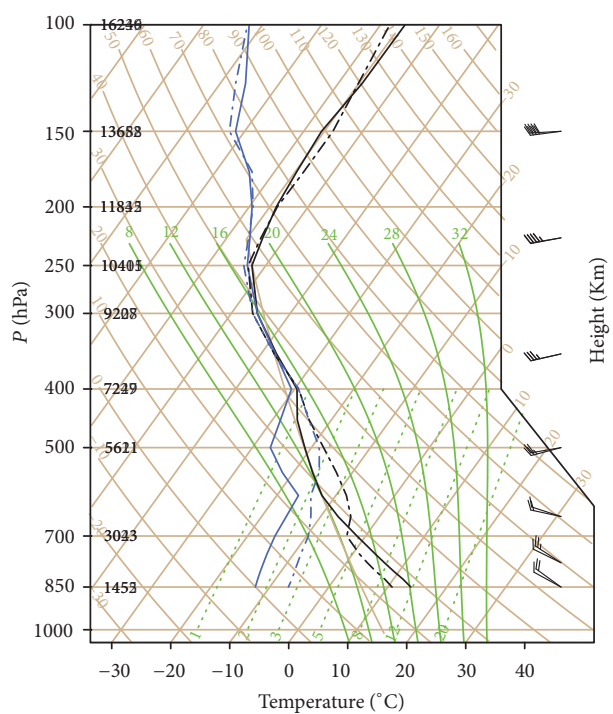

(a) 2009_4_24_00

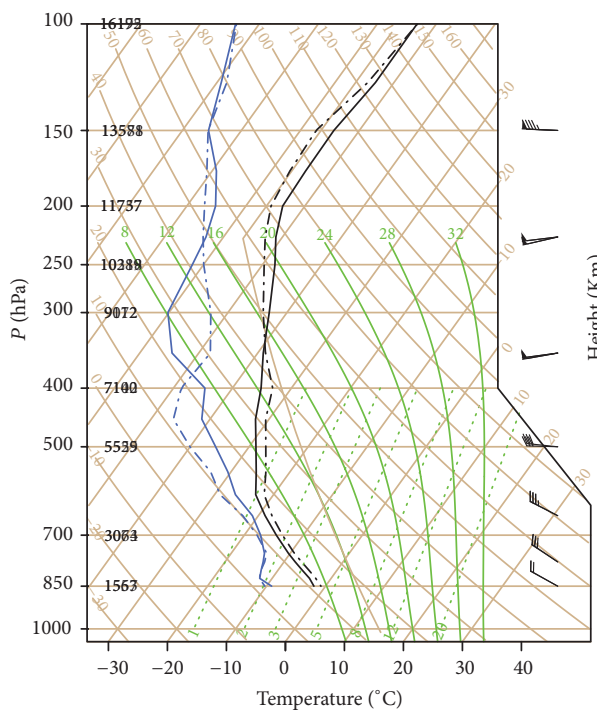

(c) 2009_4_24_12

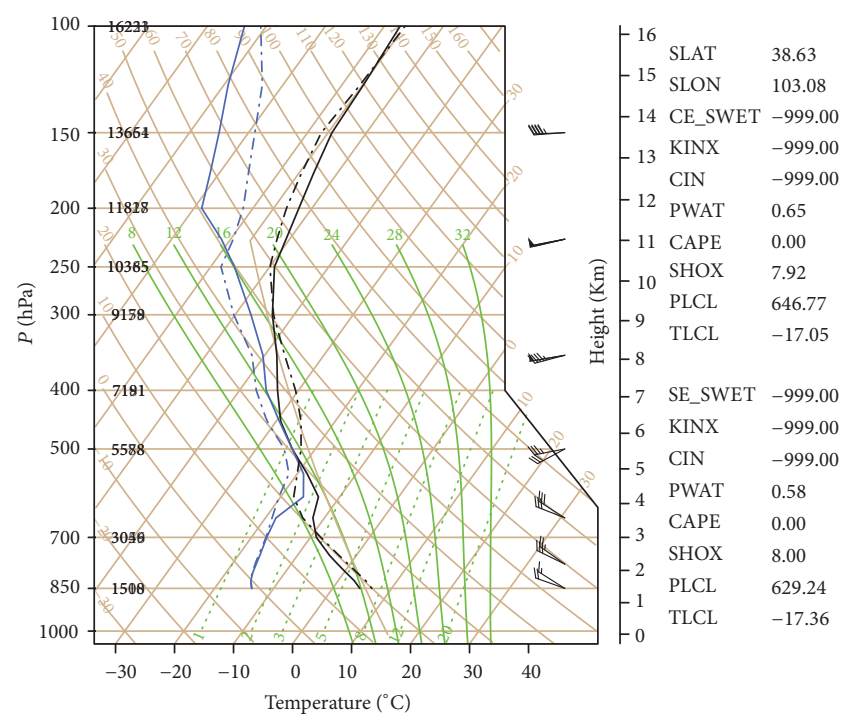

(b) 2009_4_24_06

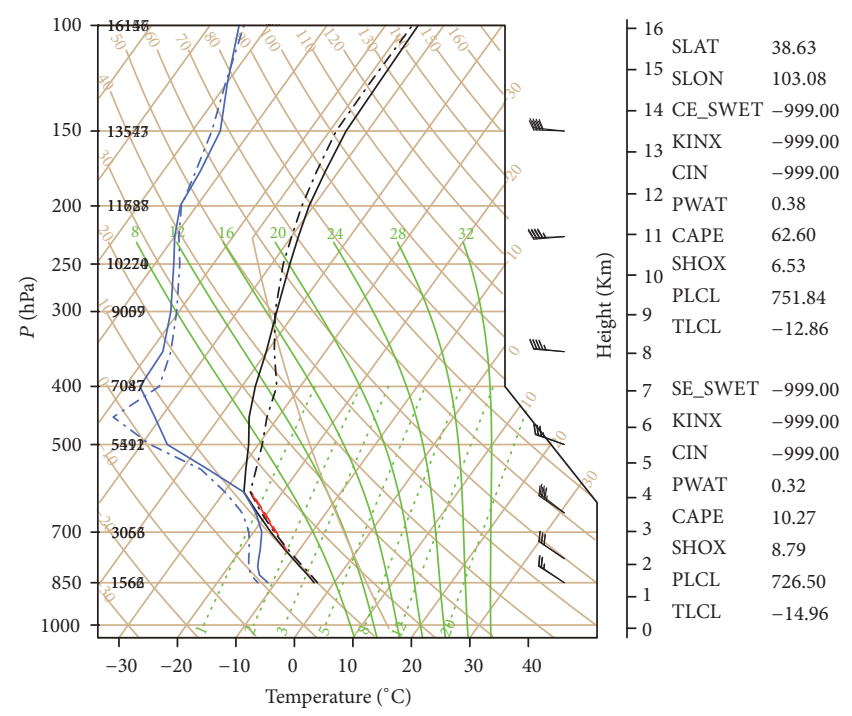

(d) 2009_4_24_18

FIGURE 7: The atmospheric stratification curve at (a) 00:00, (b) 06:00, (c) 12:00, and (d) 18:00 (UTC) on April 24, 2009, in Minqing in China $\left(42.5^{\circ} \mathrm{N}, 87.5^{\circ} \mathrm{E}\right)$ (solid line: CE; dotted line: $\mathrm{SE}$ ).

sandstorm process (Figure $7(\mathrm{c})$ ), the temperature profiles rose along the dry adiabat in the lower atmosphere; the moisture is lower and the temperature is higher in middle and lower troposphere at the sandstorm occurrence time, compared with Figures 7(a), 7(b), and 7(c). This demonstrates that the results of the SE are consistent with the observed facts.

Figure 8 shows the vertical profile of DIF (SE - CE) for regional average air temperature, shortwave radiation heating rate $\left(Q_{\mathrm{rs}}\right)$, and longwave radiation heating rate $\left(Q_{\mathrm{rl}}\right)$ in NWC $\left(37.5^{\circ} \mathrm{N}-47.5^{\circ} \mathrm{N}, 70^{\circ} \mathrm{E}-105^{\circ} \mathrm{E}\right)$ from April to June, which illustrates that the temperature changes caused by dust storms can reach the tropopause. In April (Figure 8(a)), the distinct air temperature DIF (solid line) appears around $700 \mathrm{hPa}$, which implies that the main impact of the dust storm is the temperature increase at low-level atmosphere.
This increase can reach to $300 \mathrm{hPa}$ in the troposphere. This is consistent with the results from Figure 6. Above $300 \mathrm{hPa}$, with the increase of height, the DIF becomes negative (the air temperature is lower in dust storm processes at the tropopause). The negative value reaches its minimum at $150 \mathrm{hPa}$. The change curve of the temperature DIF value indicates a value of small magnitude in May (Figure 8(b)) and June (Figure 8(c)); that is, the change of air temperature in May and June is imperceptibly small. Even though the DIF is small, the air temperature DIF remains positive below $150 \mathrm{hPa}$ and negative above $150 \mathrm{hPa}$ in May and June (i.e., the air temperature increases about $0.1 \mathrm{~K}$ below $150 \mathrm{hPa}$ and decreases about $0.1 \mathrm{~K}$ above $150 \mathrm{hPa}$ in SE in May and June). In conclusion, the climate effects of dust storms in NWC in April can last to May and June; however, the intensity is weaker in the later months. 


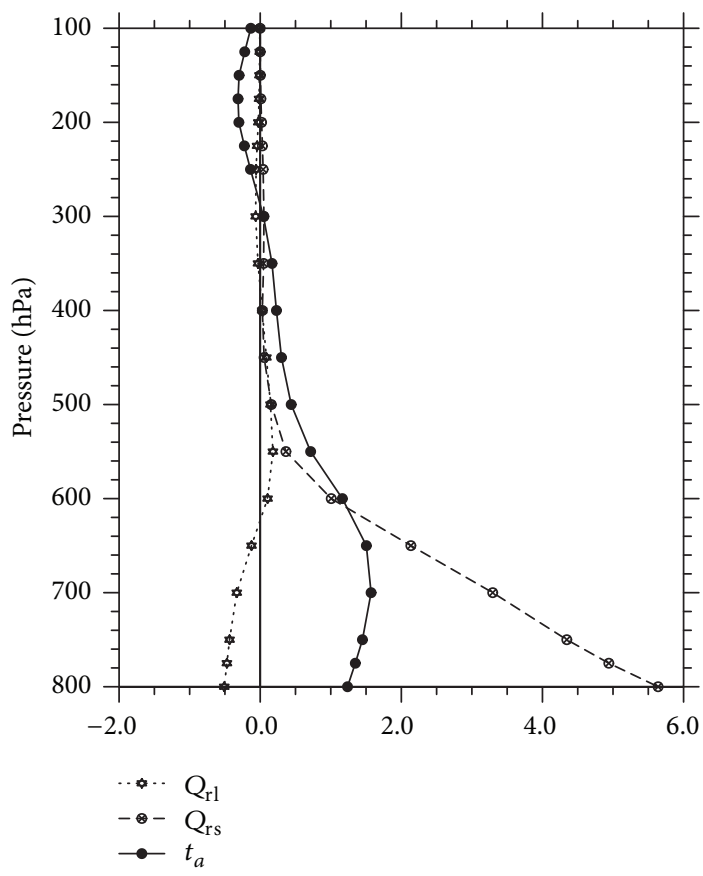

(a)

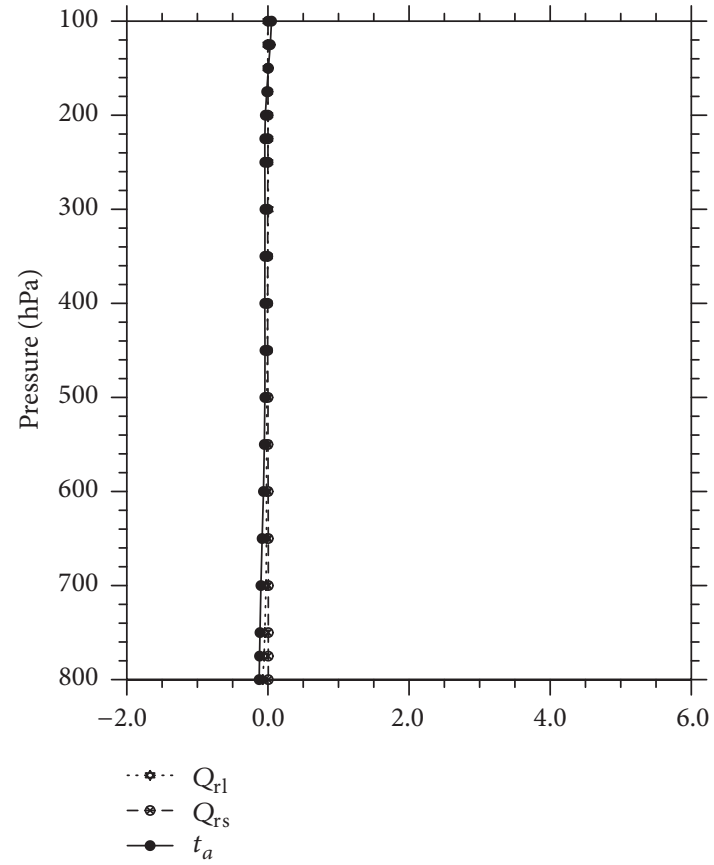

(b)

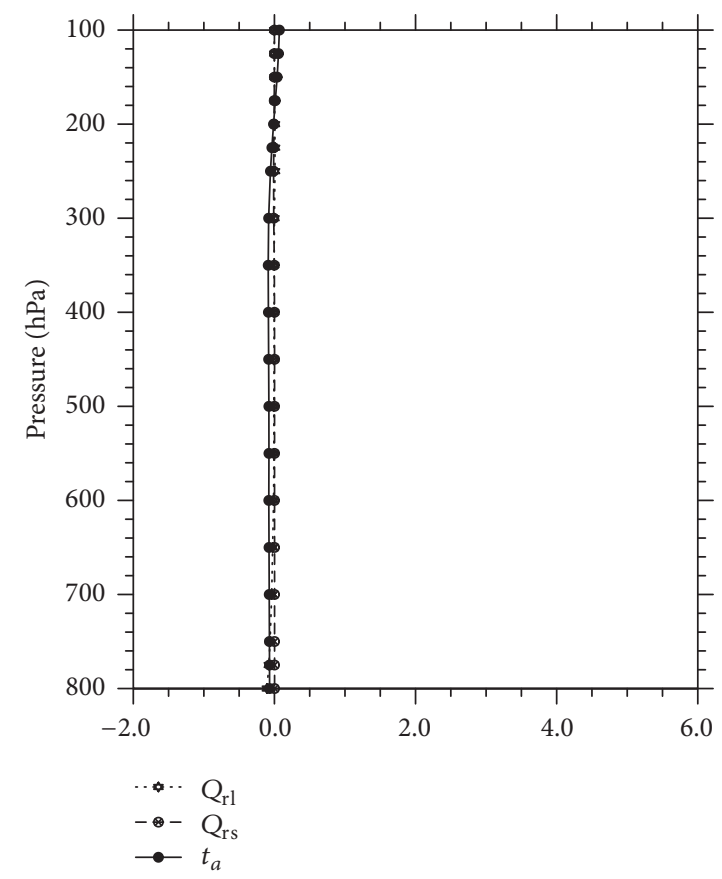

(c)

FIGURE 8: The vertical profile of DIF (SE - CE) for regional averaged air temperature $(\mathrm{K})$, shortwave heating rate $\left(Q_{\mathrm{rs}}\right)\left({ }^{\circ} \mathrm{C} \mathrm{d}^{-1}\right)$, and longwave heating rate $\left(Q_{\mathrm{rl}}\right)\left({ }^{\circ} \mathrm{C} \mathrm{d}^{-1}\right)$ in (a) April, (b) May, and (c) June, respectively, in NWC $\left(37.5^{\circ} \mathrm{N}-47.5^{\circ} \mathrm{N}, 70^{\circ} \mathrm{E}-105^{\circ} \mathrm{E}\right)$ averaged from 2001 to 2010.

4.3. Radiation Heating Rate. Because the downward shortwave radiation has been reduced, the energy is retained in the atmosphere. The $Q_{\mathrm{rs}} \mathrm{DIF}(\mathrm{SE}-\mathrm{CE}$ ) remains positive and decreases below $400 \mathrm{hPa}$ in April (Figure 8(a), dashed line). For example, $Q_{\mathrm{rs}}$ in sandstorm weather is higher than in non-sandstorm weather, which implies that the air at the low-level atmosphere is heated by the reduced radiation energy. Moreover, after reducing the downward radiation, less energy reached the surface, so the land becomes cooler and emits less longwave radiation energy. $Q_{\mathrm{rl}}$ during the sandstorm is smaller than during non-sandstorm weather at below $600 \mathrm{hPa}$. The $\mathrm{Q}_{\mathrm{rl}} \mathrm{DIF}(\mathrm{SE}-\mathrm{CE}$ ) decreases with the height from the surface to $600 \mathrm{hPa}$ in April (Figure 8(a), dotted line). The $Q_{\mathrm{rl}} \mathrm{DIF}(\mathrm{SE}-\mathrm{CE})$ approaches 0 between 
Units: $\operatorname{deg} \mathrm{C} / \mathrm{d}$

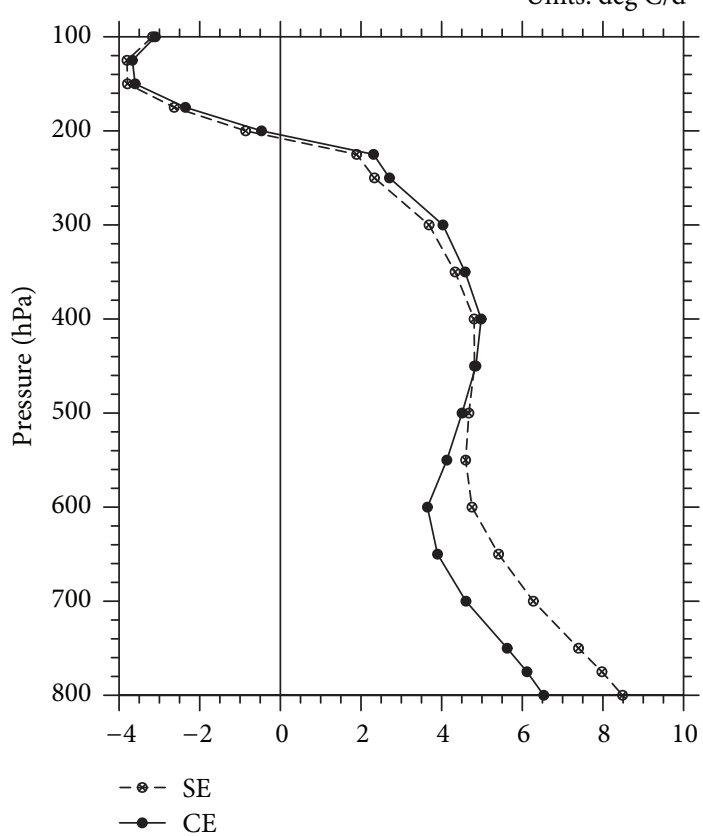

(a) Apparent heat source

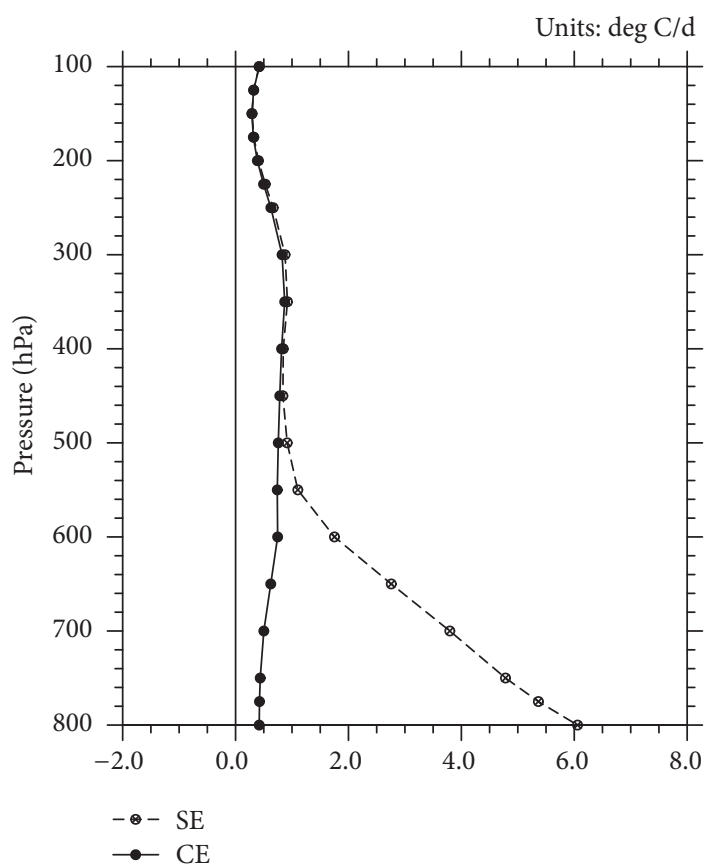

(c) $Q_{\mathrm{rs}}$

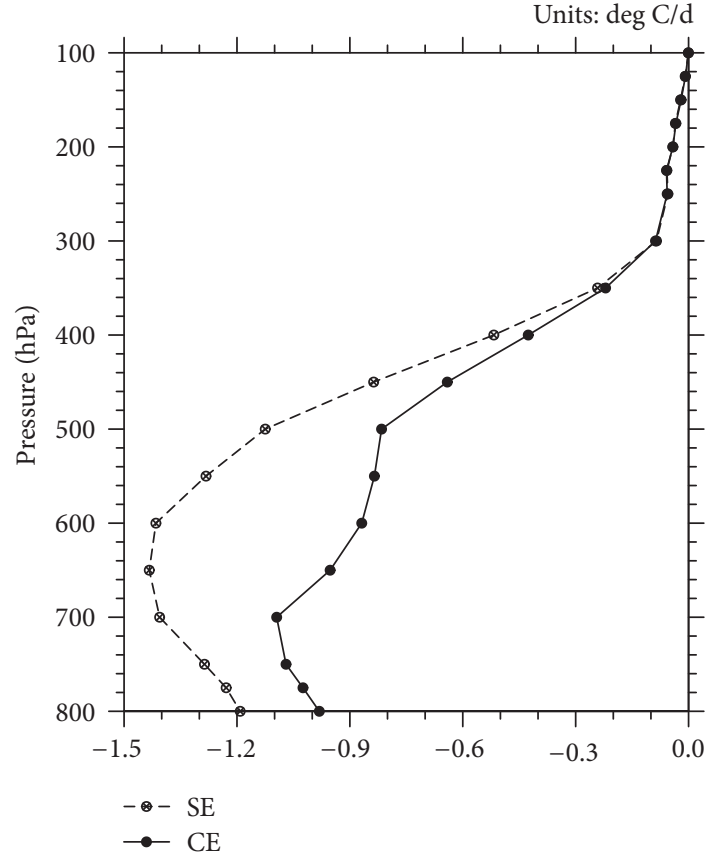

(b) Apparent moisture sink

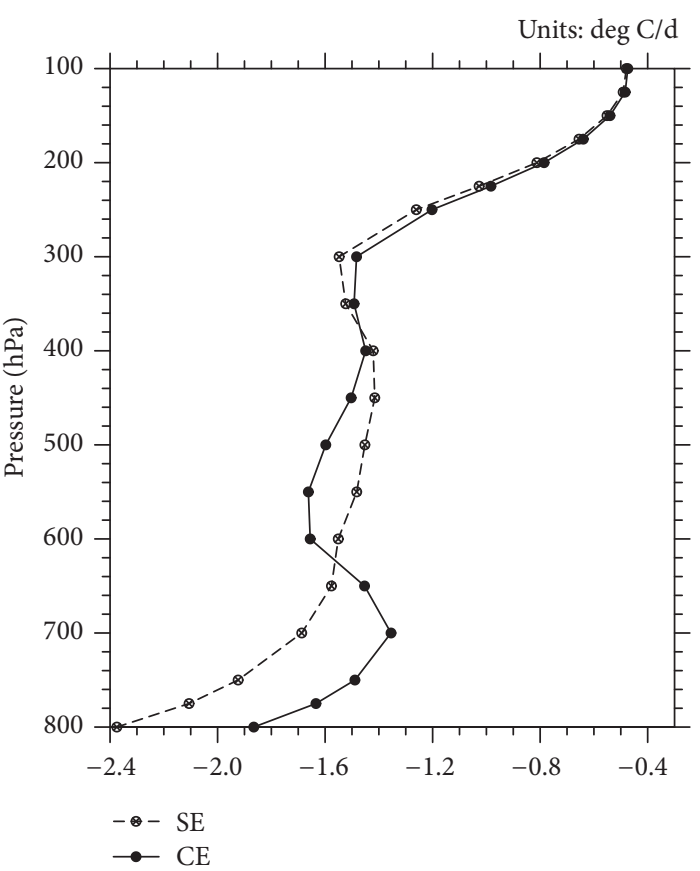

(d) $Q_{\mathrm{rl}}$

FIGURE 9: The vertical profile of (a) apparent heat source $\left(Q_{1} /\left({ }^{\circ} \mathrm{C} \mathrm{d}-1\right)\right)$; (b) apparent moisture sink $\left(Q_{2} /\left({ }^{\circ} \mathrm{C} \mathrm{d} \mathrm{d}^{-1}\right)\right)$; (c) shortwave radiation heating rate $\left(Q_{\mathrm{rs}} /\left({ }^{\circ} \mathrm{C} \mathrm{d}{ }^{-1}\right)\right)$; (d) longwave radiation heating rate $\left(Q_{\mathrm{rl}} /\left({ }^{\circ} \mathrm{Cd}^{-1}\right)\right)$ in $\mathrm{SE}$ and $\mathrm{CE}$, respectively, in April averaged from 2001 to 2010.

$600 \mathrm{hPa}$ and $100 \mathrm{hPa}$ indicating that $\mathrm{Q}_{\mathrm{rl}}$ is reduced in dust storms in the lower levels of the atmosphere because of the cooling effects of the land, and the influence is decay with the height. $Q_{\mathrm{rs}}$ and $Q_{\mathrm{rl}}$ DIF in May (Figure 8(b)) and June (Figure $8(c)$ ) are near to 0 because the reduction of downward shortwave radiation ceases. In contrast, in April (Figure 8(a)), the $Q_{\mathrm{rs}}$ DIF is one order of magnitude larger than $Q_{\mathrm{rl}}$ DIF (i.e., the heating effects of $Q_{\mathrm{rs}}$ in the atmosphere are more important than the cooling effects of $Q_{\mathrm{rl}}$ near the surface).

4.4. The Change of Heating. Based on the regional average of NWC $\left(37.5^{\circ} \mathrm{N}-47.5^{\circ} \mathrm{N}, 70^{\circ} \mathrm{E}-105^{\circ} \mathrm{E}\right)$, the vertical profile of the apparent heat source $\left(Q_{1}\right)$ in April (Figure 9(a)) is maintained positive below $200 \mathrm{hPa}$ and the value in $\mathrm{SE}$ 


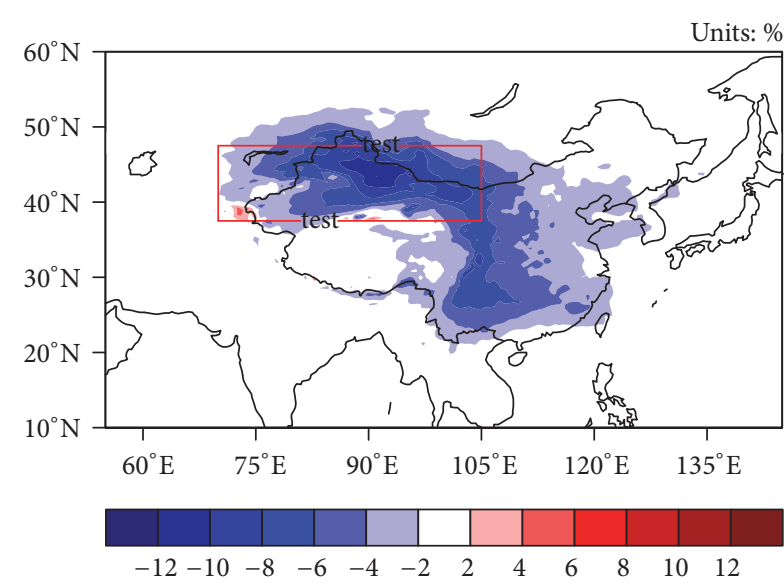

(a) Relative humidity

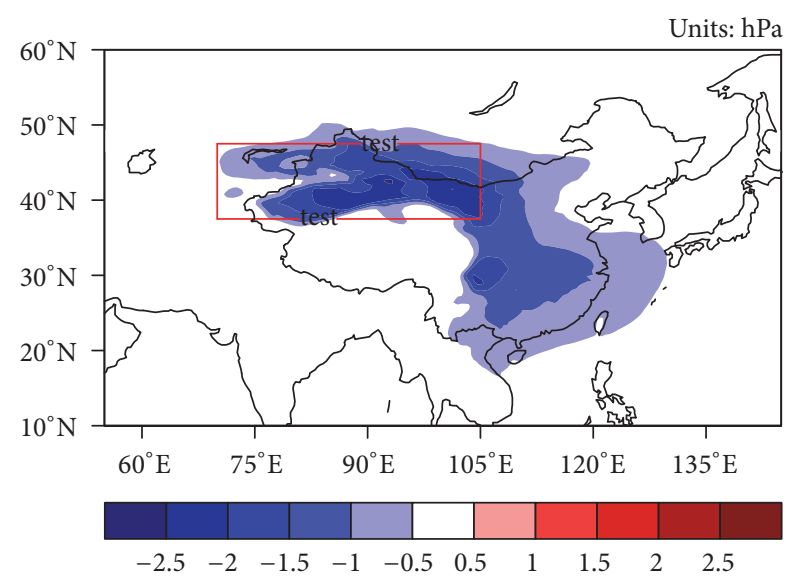

(c) Surface pressure

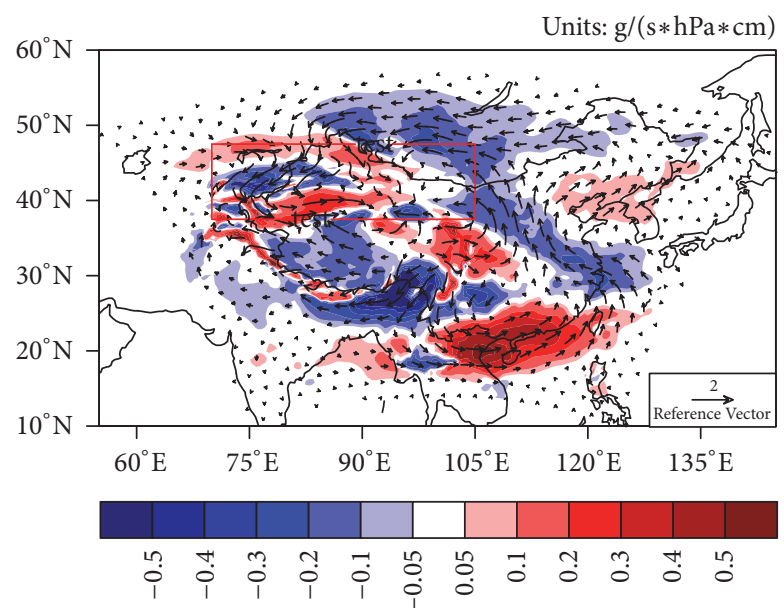

(b) Water vapor flux

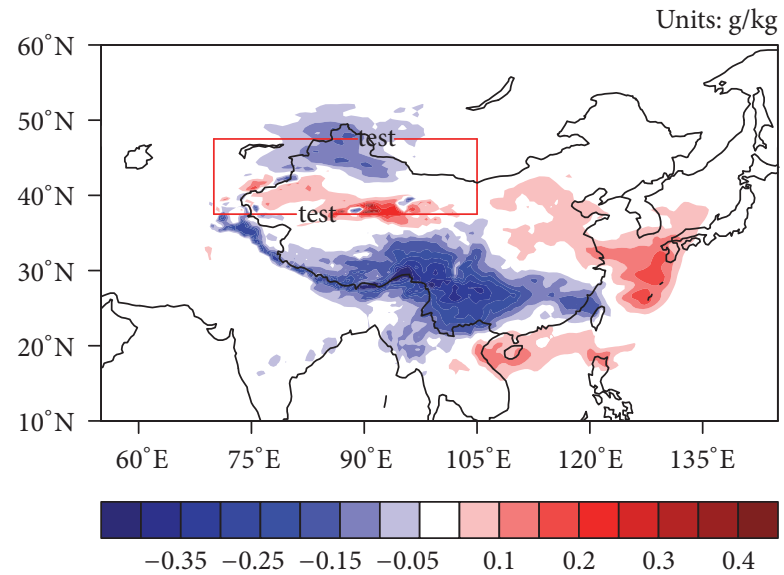

(d) Specific humidity

Figure 10: (a) The DIF (SE - CE) of $700 \mathrm{hPa}$ relative humidity (\%); (b) $700 \mathrm{hPa}$ water vapor flux $\left(\mathrm{g} \mathrm{s}^{-1} \cdot \mathrm{hPa}^{-1} \cdot \mathrm{cm}^{-1}\right)$; (c) surface pressure (hPa); and (d) $700 \mathrm{hPa}$ specific humidity $\left(\mathrm{g} \mathrm{kg}^{-1}\right)$ in April averaged from 2001 to 2010.

(dashed line) is larger than in the CE (solid line) below $400 \mathrm{hPa}$. This indicates that the atmosphere below $200 \mathrm{hPa}$ is a heat source and the DRE of dust aerosols in sandstorms enhances the diabatic heating effect below $400 \mathrm{hPa}$ in SE. $Q_{1}$ becomes negative above $200 \mathrm{hPa}$, indicating that the tropopause in April in NWC is a cold source. The apparent moisture sink $\left(Q_{2}\right)$ in NWC maintains a negative value in April (Figure 9(b)), which means that the moisture loss is more than moisture influx in the arid area. This phenomenon may be because of the high evaporation capacity in NWC (i.e., the same reason that arid conditions were formed). The DRE of the dust aerosols in sandstorms enhances the dry conditions indicated by the lower $Q_{2}$ in SE than in CE. This is because the increase of air temperature may enhance the evaporation. In contrast, the magnitude of $Q_{1}$ is one order of magnitude larger than $Q_{2}$, which is due to the arid environment. $Q_{\mathrm{rs}}$ is clearly enhanced in SE below $450 \mathrm{hPa}$ and remains positive (Figure 9(c)) because the DRE of dust aerosols in sandstorms can enhance $Q_{\mathrm{rs}}$ through enhancing the scattering of radiation, thus heating the air. However, $Q_{\mathrm{rl}}$ is negative because of the cold source effect of the surface and is smaller below $650 \mathrm{hPa}$ in SE than in CE (Figure 9(d)). This phenomenon highlights that the effects of the DRE of dust aerosols in sandstorms could enhance the cold source effects from the surface. The reason for the enhancement of $Q_{\mathrm{rl}}$ between $650 \mathrm{hPa}$ and $350 \mathrm{hPa}$ is related to the enhancement of longwave radiation emitted from the low-level atmosphere because of the increase of air temperature in the low-level atmosphere. The above results show that the DRE of dust aerosols in sandstorms can enhance the heat source effects and dry conditions in NWC, through heating the air in the middle and low-level troposphere and enhancing the cold source effects of the surface.

4.5. The Changes of Water Vapor Flux. The DIF (SE - CE) distributions of $700 \mathrm{hPa}$ relative humidity, $700 \mathrm{hPa}$ water vapor flux, surface pressure, and $700 \mathrm{hPa}$ specific humidity in April averaged from 2001 to 2010 are shown in Figure 10. There were no clear changes in May and June (figures are omitted). In the NWC and south China, the 


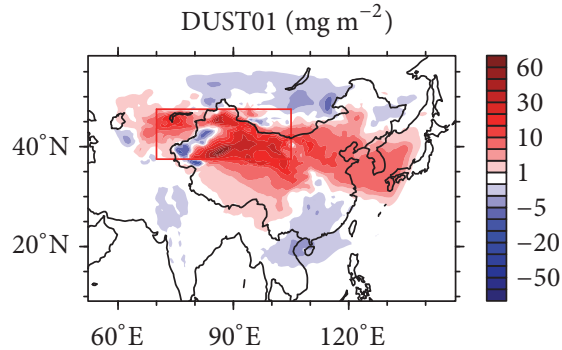

(a) April

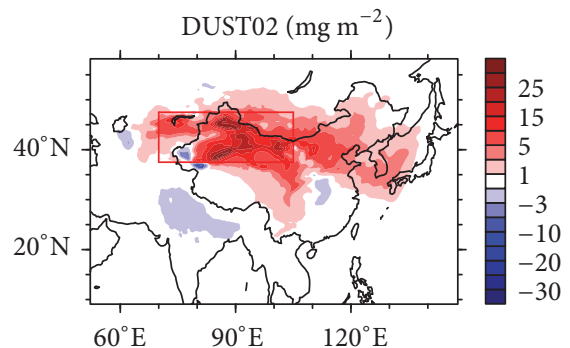

(d) April

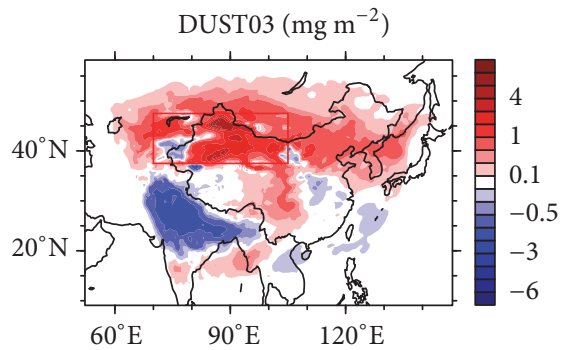

(g) April

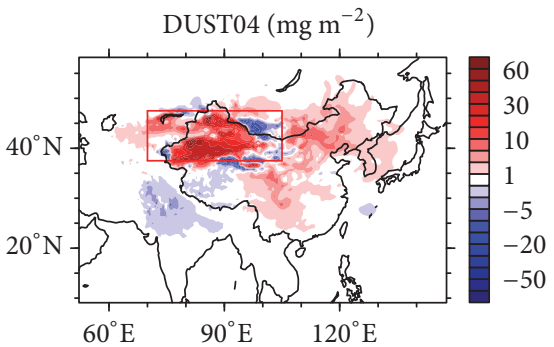

(j) April

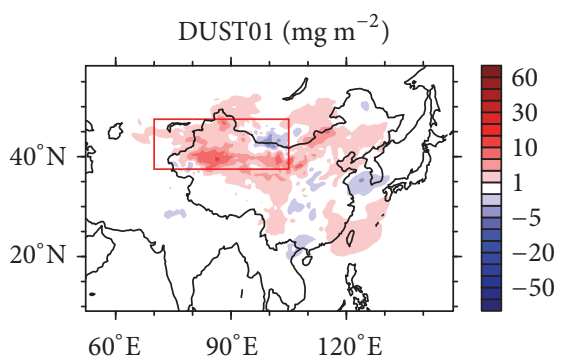

(b) May

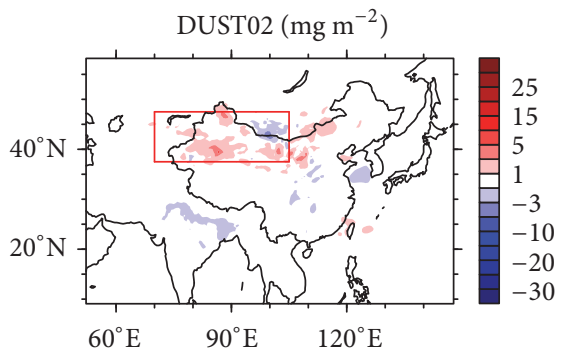

(e) May

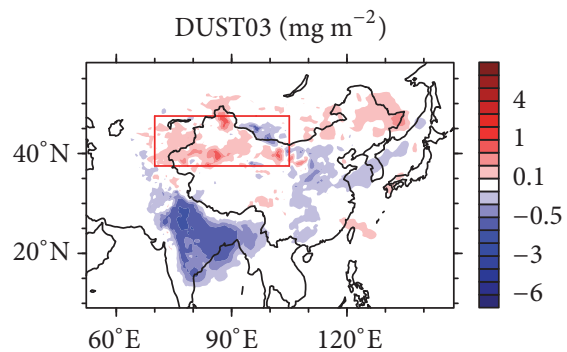

(h) May

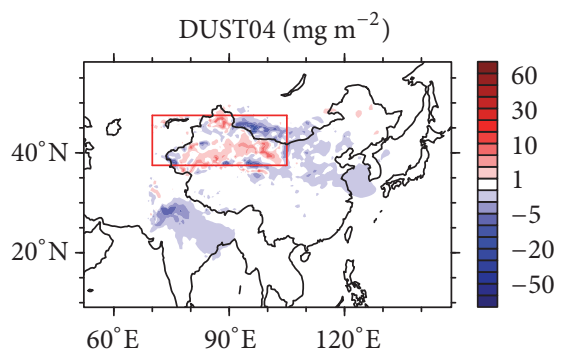

(k) May

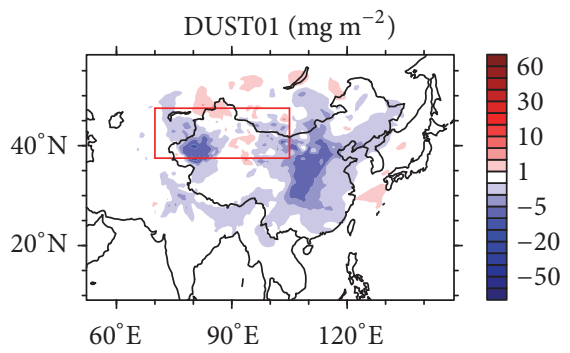

(c) June

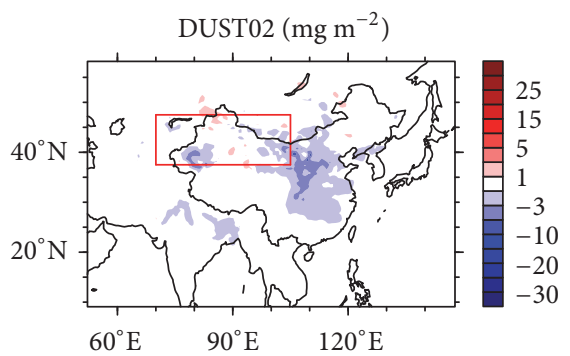

(f) June

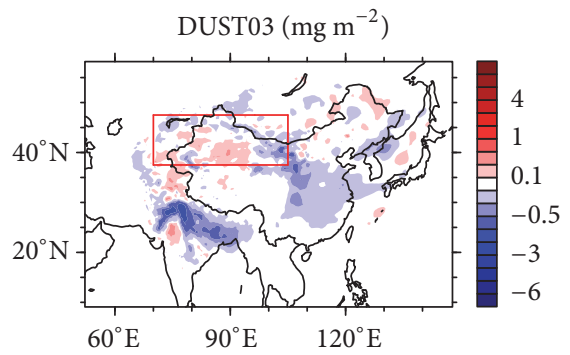

(i) June

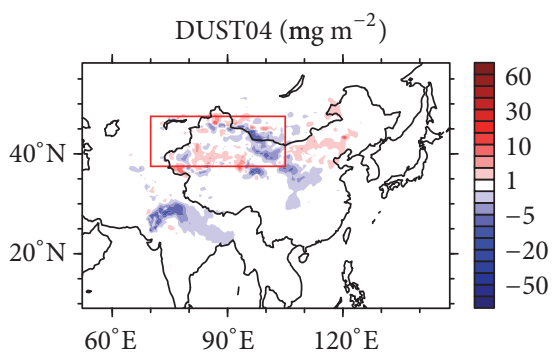

(l) June

FigURE 11: The DIF (SE - CE) of the tracer total burden $\left(\mathrm{mg} \mathrm{m}^{-2}\right)$ of the four dust bins (DUST01-DUST04) in April, May, and June averaged from 2001 to 2010.

relative humidity decreased considerably (Figure 10(a)). This is because the increased temperature led to an increase in the saturated vapor pressure point. In this case, the water vapor in the air becomes more difficult to coagulate. This effect may well correspond to the precipitation distribution during the sandstorm process in NWC. The change of the surface pressure is reflected more clearly in NWC and south China (Figure 10(c)); the rise of air temperature led to the swell of the air and thus led to the reduction of the surface pressure. The DIF (SE - CE) of water vapor flux field expresses changes in the ability of the air to transport water vapor (Figure 10(b)). Combined with the change of wind field, it clearly shows that the water vapor flux decreases north of the experimental region and increases south of the experimental region in SE. The wind can be seen to strengthen the convergence in the east of NWC and strengthen the divergence in the west of the experimental region. This possibly relates to the topographic condition and large scale circulation background; however, the change mechanisms of water vapor flux are complex and the mechanism causing the response requires further research. The DIF (SE - CE) distribution of $700 \mathrm{hPa}$ specific humidity in air is consistent with the DIF (SE - CE) of the water vapor flux field; the specific humidity decreases in north NWC and increases in south NWC; however, these mechanisms are as complex as the water vapor flux and 
further research is required before they can be examined in further detail.

4.6. The Changes of Dust Tracer Total Burden. The analysis above emphasizes that the DRE of dust aerosols during a sandstorm in NWC could enhance the air temperature and reduce the moisture. For example, the environment in NWC will become warmer and dryer if sandstorms occur more frequently, last longer, and have a stronger intensity. Under these conditions, the climate effects of DRE in sandstorms may react to the emission of dust from the surface. Figure 11 shows the DIF of tracer total burden of the 4 dust bins in RegCM4 in April, May, and June averaged from 2001 to 2010. The 4 dust bins in RegCM4 are used to calculate the emission and tracer of dust aerosols with 0.01-, 1.00-, 2.50, and 5.00-micrometer particle diameter. The magnitude of the dust tracer total burdens indicates that the DIF (SE $\mathrm{CE}$ ) of the 0.01 and 5.00 micrometers size dust aerosols tracer burdens are largest in the simulation, the DIF (SE - CE) of 1.00 micrometers size aerosols tracer burden is in the middle, and the DIF (SE - CE) of 2.50 micrometers size aerosols tracer burden is the shortest. Combining the analysis, the burdens of the 4 different dust bins increase strongly in NWC in April, and they flow to downstream areas such as Northeast and Southwest China. This increase can last to May and June, although the increase is smaller in these later months.

\section{Summary and Conclusion}

Dust storms frequently occur in NWC, which leads to a hostile environment and weather. The pollution and cooling are well known; however, the influence extent and duration of the continuous sandstorms events are less understood and were investigated for NWC in this study. We specifically investigated the DRE from dust aerosols in sandstorms in the NWC region. Through combing simulations and observations, we described the basic radiation feature in the sandstorm as follows: the highest frequency month of sandstorms in NWC is in April, and the global radiation average reduces $20-60 \%$ during the sandstorm process. The RegCM4 (ICTP) was used to simulate the climate effects of dust aerosols in NWC from 01 January 2001 to 01 March 2011 with the first 2 months as the spin-up time. In SE, the downward shortwave radiation was reduced $40 \%$ in the bottom 8 layers in $\sigma$ vertical coordinate which is equivalent to below $700 \mathrm{hPa}$ every April to simulate the DRE of dust aerosols during sandstorms. The results show that the reduced shortwave radiation by dust aerosols can heat the middle and low troposphere and forms a cooler source at Earth's surface, thus changing $Q_{\mathrm{rs}}$ and $Q_{\mathrm{rl}}$. The air temperature below $300 \mathrm{hPa}$ increases and that above $300 \mathrm{hPa}$ decreases during sandstorms; the strongest enhancement is at about $700 \mathrm{hPa}$. Simultaneously, because of the short reach of shortwave radiation to the surface, the surface becomes a cold source and reduces the emission of longwave radiation. The change of the air temperature and surface conditions at NWC in April can affect the climate downstream in areas such as Northeast and Southwest China and last to May and June.

Through analyzing the atmospheric stratification change during a sandstorm process in Minqin, we found that the short of downward radiation caused by dust storm can enhance the air temperature and reduce the moisture in the daytime in the middle and lower atmosphere. The analysis of the change in apparent heat source $\left(Q_{1}\right)$ and apparent moisture sink $\left(Q_{2}\right)$ in April and NWC shows that the conditions in NWC become warmer and dryer in SE during sandstorms. This suggests that the DRE of dust aerosols in sandstorms can enhance the heat source effects and cause the moisture loss in NWC. This is likely to cause an intensification of the drying trend. The changes of $700 \mathrm{hPa}$ relative humidity, water vapor flux, surface pressure, and $700 \mathrm{hPa}$ specific humidity further prove the points discussed above. We have found that the DRE of dust aerosols in sandstorms has a reaction on the dust aerosols emissions; that is, this effect could enhance the dust storm and form a self-feedback loop. These effects of sandstorms in April in NWC can flow to downstream areas such as Northeast and Southwest China and can last to May and June, but the intensity of the effects weakens in these later months.

\section{Conflicts of Interest}

The authors declare that there are no conflicts of interest regarding the publication of this paper.

\section{Acknowledgments}

This work was supported by Industry Special Projects of the China Meteorological Administration (CMA) (GYHY201506001) and National Natural Science Foundation of China (nos. 41471034 and 41661144017). The authors would like to thank Accdon for their linguistic assistance during the preparation of this manuscript.

\section{References}

[1] T. T. Warmer, Desert Meteorology, Cambridge University Press, Cambridge, UK, 2004.

[2] T. F. Stocker, D. Qin, G.-K. Plattner et al., Eds., Climate Change 2013: The Physical Science Basis. Contribution of Working Group I to the Fifth Assessment Report of the Intergovernmental Panel on Climate Change, IPCC, 2013.

[3] M. Yoshioka, N. M. Mahowald, A. J. Conley et al., "Impact of desert dust radiative forcing on sahel precipitation: relative importance of dust compared to sea surface temperature variations, vegetation changes, and greenhouse gas warming," Journal of Climate, vol. 20, no. 8, pp. 1445-1467, 2007.

[4] G. R. Foltz and M. J. McPhaden, "Impact of Saharan dust on tropical North Atlantic SST," Journal of Climate, vol. 21, no. 19, pp. 5048-5060, 2008.

[5] J. P. Mulcahy, D. N. Walters, N. Bellouin, and S. F. Milton, "Impacts of increasing the aerosol complexity in the Met Office global numerical weather prediction model," Atmospheric Chemistry and Physics, vol. 14, no. 9, pp. 4749-4778, 2014. 
[6] N. Jehuda and C. Ariel, "Climate effects of aerosol layers in relation to solar radiation," Journal of Applied Meteorology, vol. 11, pp. 651-657, 1972.

[7] J. Huang, T. Wang, W. Wang, Z. Li, and H. Yan, "Climate effects of dust aerosols over East Asian arid and semiarid regions," Journal of Geophysical Research: Atmospheres, vol. 119, no. 19, pp. 11398-11416, 2014.

[8] S. Kaspari, P. A. Mayewski, M. Handley et al., "A high-resolution record of atmospheric dust composition and variability since A.D. 1650 from a Mount Everest ice core," Journal of Climate, vol. 22, no. 14, pp. 3910-3925, 2009.

[9] J. H. Seinfeld, G. R. Carmichael, R. Arimoto et al., "ACE-ASIA: regional climatic and atmospheric chemical effects of Asian dust and pollution," Bulletin of the American Meteorological Society, vol. 85, no. 3, pp. 367-380, 2004.

[10] S. Zhao, H. Zhang, S. Feng, and Q. Fu, "Simulating direct effects of dust aerosol on arid and semi-arid regions using an aerosolclimate coupled system," International Journal of Climatology, vol. 35, no. 8, pp. 1858-1866, 2015.

[11] C. Wang, J. Hu, and S. Jin, "The vapor characteristics in a dust storm and verification of WRF hindcast," Journal of Desert Research, vol. 33, no. 1, pp. 205-213, 2013 (Chinese).

[12] M. N. Islam and M. Almazroui, "Direct effects and feedback of desert dust on the climate of the Arabian Peninsula during the wet season: a regional climate model study," Climate Dynamics, vol. 39, no. 9-10, pp. 2239-2250, 2012.

[13] H. Sun, Z. Pan, and X. Liu, "Numerical simulation of spatialtemporal distribution of dust aerosol and its direct radiative effects on East Asian climate," Journal of Geophysical Research Atmospheres, vol. 117, no. 13, Article ID D13206, 2012.

[14] R. B. Seigel and S. C. Van Den Heever, "Dust lofting and ingestion by supercell storms," Journal of the Atmospheric Sciences, vol. 69, no. 5, pp. 1453-1473, 2012.

[15] R. L. Miller and I. Tegen, "Climate response to soil dust aerosols," Journal of Climate, vol. 11, no. 12, pp. 3247-3267, 1998.

[16] J. Xin, W. Zhang, and J. Yuan, "Study on attenuation of direct solar flux by sand-dust aerosol in Tengger Desert," Journal of Desert Research, vol. 23, pp. 311-315, 2003 (Chinese).

[17] S. Li, L. Hu, and Q. He, "Analysis on characteristics of radiation and meteorological elements during a strong sandstorm passing Taklimakan Desert," Desert and Oasis Meteorology, vol. 5, no. 4, pp. 26-30, 2011 (Chinese).

[18] D. Kong, Q. He, and R. Zhang, "Analysis on radiation forcing of dust aerosol in a spring typical dust storm event in the centre of TaklaMakan Desert," Arid Meteorology, vol. 26, no. 2, pp. 36-40, 2008 (Chinese).

[19] Z. Shen and L. Wei, "Radiative effects of atmospheric dust aerosol in Northwest China," Chinese Journal of Atmospheric Sciences, vol. 27, no. 4, pp. 541-548, 2000 (Chinese).

[20] B. Hu, Y. Wang, and X. He, "Variation properties of Earth's surface solar radiation during a strong dust storm in Beijing," Climate and Environmental Research, vol. 10, no. 2, pp. 265-274, 2005 (Chinese).

[21] J. Hu, H. Cui, and Z. Tang, "Temporal and spatial characteristics of Sandstorm in China and the influnces of human activities on its development trend," Journal of Natural Disasters, vol. 8, no. 4, pp. 49-56, 1999 (Chinese).

[22] Y.-D. Fan, P.-J. Shi, J.-H. Zhou, and M.-X. Ji, "Research on change of dust storm in China in recent 50 years," Journal of Natural Disasters, vol. 14, no. 3, pp. 22-28, 2005 (Chinese).
[23] Y. Shi, Y. Shen, and R. Hu, "Preliminary study on signal, impact and foreground of climatic shift from warm-dry to warm-humid in Northwest China," Journal of Glaciology and Geocryology, vol. 24, no. 3, pp. 219-226, 2002 (Chinese).

[24] Y. Shi, Y. Shen, and D. Li, "Discussion on the present climate change from warm-dry to warm-wet in Northwest China," Quaternary Sciences, vol. 23, no. 2, pp. 152-164, 2003 (Chinese).

[25] X. Wang, J. Huang, M. Ji, and K. Higuchi, "Variability of East Asia dust events and their long-term trend," Atmospheric Environment, vol. 42, no. 13, pp. 3156-3165, 2008.

[26] A. Holtslag, E. Bruijn, and H. Pan, "A high resolution air mass transformation model for shortrange weather forecasting," Monthly Weather Review, vol. 118, pp. 1561-1575, 1990.

[27] K. Emanuel, "A scheme for representing cumulus convection in large-scale models," Journal of the Atmospheric Sciences, vol. 48, no. 21, pp. 2313-2335, 1991.

[28] F. Giorgi, E. Coppola, F. Solmon et al., "RegCM4: model description and preliminary tests over multiple CORDEX domains," Climate Research, vol. 52, no. 1, pp. 7-29, 2012.

[29] D. Dee, S. M. Uppala, A. J. Simmons et al., “The ERA-Interim reanalysis: configuration and performance of the data assimilation system," Quarterly Journal of the Royal Meteorological Society, vol. 137, no. 656, pp. 553-597, 2011.

[30] J. Kiehl, J. Hack, G. Bonan et al., "Description of the ncar community climate model (ccm3)," Tech. Rep. NCAR/TN420+STR, National Center for Atmospheric Research, Boulder, Colo, USA, 1996.

[31] R. Dickinson, P. Kennedy, A. Henderson-Sellers, and M. Wilson, "Biosphere-atmosphere transfer scheme (bats) for the ncar community climate model," Tech. Rep. NCARE/TN-275+STR, National Center for Atmospheric Research, 1986.

[32] B. Laurent, B. Marticorena, G. Bergametti, J. F. Léon, and N. M. Mahowald, "Modeling mineral dust emissions from the Sahara desert using new surface properties and soil database," Journal of Geophysical Research Atmospheres, vol. 113, no. 14, Article ID D14218, 2008.

[33] S. C. Alfaro and L. Gomes, "Modeling mineral aerosol production by wind erosion: emission intensities and aerosol size distributions in source areas," Journal of Geophysical Research Atmospheres, vol. 106, no. 16, pp. 18075-18084, 2001.

[34] J. Huang, Q. Fu, J. Su et al., "Taklimakan dust aerosol radiative heating derived from CALIPSO observations using the FuLiou radiation model with CERES constraints," Atmospheric Chemistry and Physics, vol. 9, no. 12, pp. 4011-4021, 2009. 

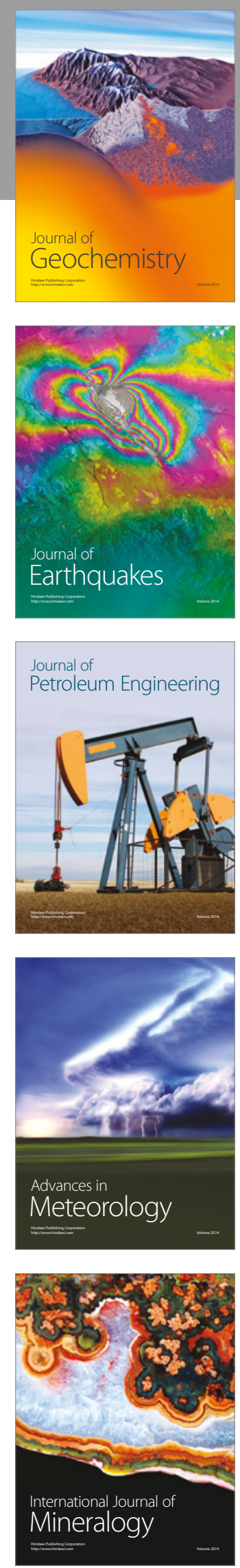
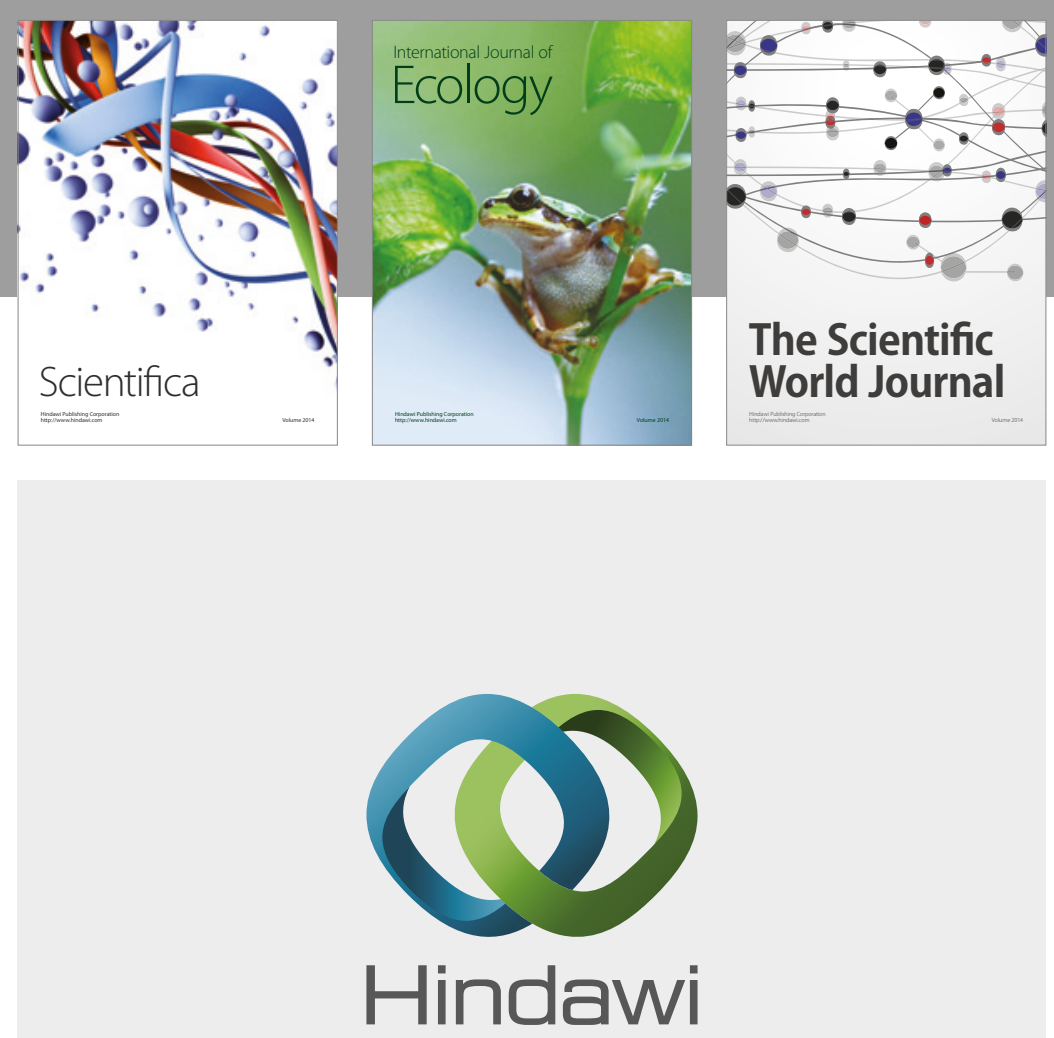

Submit your manuscripts at

https://www.hindawi.com
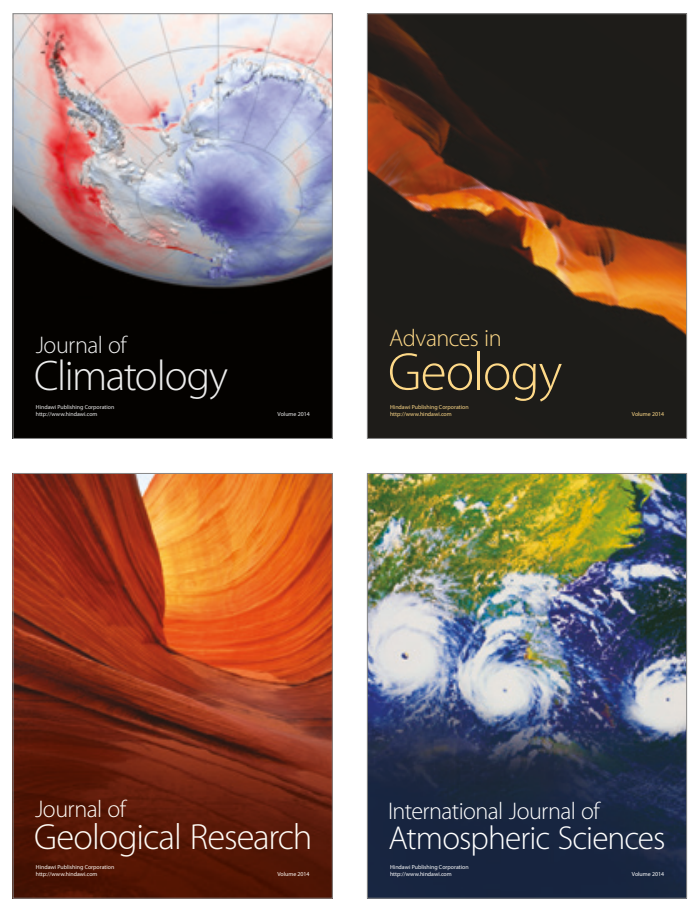

The Scientific

World Journal
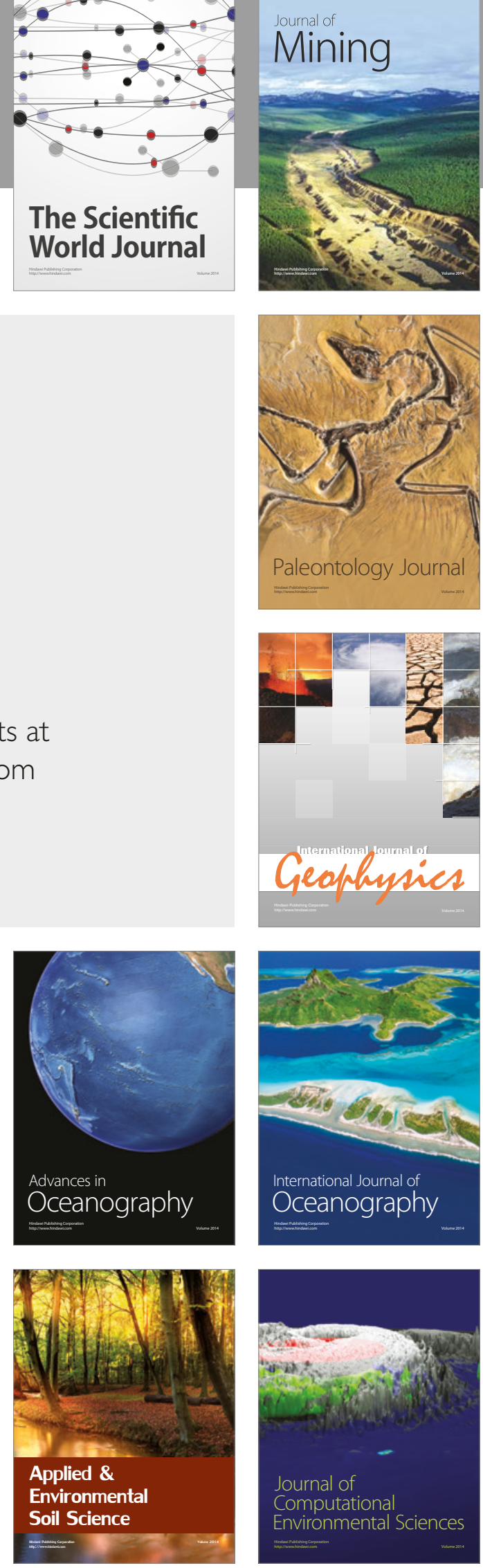